\title{
Protection of nascent DNA at stalled replication forks is mediated by phosphorylation of RIF1 intrinsically disordered region
}

\author{
Balasubramanian S. 1,2,\#, Andreani M. ${ }^{1,2, \#}$, Andrade J.G. ${ }^{1}$, Saha T. ${ }^{1,2}$, Garzón \\ J. ${ }^{3,4}$, Zhang W. ${ }^{5}$, Rahjouei A. ${ }^{1}$, Rosen D.B. ${ }^{6,7}$, Chait B.T. ${ }^{5}$, Donaldson A.D. ${ }^{3}$, \\ and Di Virgilio M. ${ }^{1,8, *}$
}

${ }^{1}$ Laboratory of Genome Diversification \& Integrity, Max Delbrück Center for

Molecular Medicine in the Helmholtz Association, Berlin 13125, Germany

${ }^{2}$ Freie Universität Berlin, Berlin 14195, Germany

${ }^{3}$ Institute of Medical Sciences, University of Aberdeen, Foresterhill, Aberdeen AB25 2ZD, UK

${ }^{4}$ Current address: Adrestia Therapeutics Ltd., Babraham Research

Campus, Cambridge CB22 3AT, UK

${ }^{5}$ Laboratory of Mass Spectrometry and Gaseous Ion Chemistry, The

Rockefeller University, New York, NY 10065, USA

'Laboratory of Molecular Immunology, The Rockefeller University, New York, NY 10065, USA

${ }^{7}$ Current address: Department of Radiation Oncology, Dana-Farber Cancer

Institute, Brigham and Women's Hospital, Boston, MA 02115, USA

${ }^{8}$ Charité-Universitätsmedizin Berlin, Berlin 10117, Germany

\# These authors contributed equally

*Correspondence: michela.divirgilio@mdc-berlin.de 


\footnotetext{
Abstract

2

RIF1 is a multifunctional protein that plays key roles in the regulation of DNA processing. During repair of DNA double-strand breaks (DSBs), RIF1 functions in the 53BP1-Shieldin pathway that inhibits resection of DNA ends to modulate the cellular decision on which repair pathway to engage. Under conditions of replication stress, RIF1 protects nascent DNA at stalled replication forks from degradation by the DNA2 nuclease. How these RIF1 activities are regulated at the post-translational level has not yet been elucidated. Here, we identified a cluster of conserved ATM/ATR consensus $S Q$ motifs within the intrinsically disordered region (IDR) of mouse RIF1 that are phosphorylated in proliferating $B$ lymphocytes. We found that phosphorylation of the conserved IDR SQ cluster is dispensable for the inhibition of DSB resection by RIF1, but is essential to counteract DNA2dependent degradation of nascent DNA at stalled replication forks. Therefore, our study identifies a key molecular switch that enables the genomeprotective function of RIF1 during DNA replication stress.

\section{Keywords}

RIF1, SQ motifs, intrinsically disordered region, DSB resection inhibition, DNA replication fork protection
} 


\section{Introduction}

Control of DNA processing is a crucial determinant for the preservation of genome stability during both DNA repair and DNA replication. In the context of DNA double-strand break (DSB) repair, nucleolytic processing of DNA ends acts as a key defining step in the regulation of repair pathway choice (Chapman et al., 2012; Scully et al., 2019). Extensive 5' to 3' resection of DSBs inhibits repair by nonhomologous end joining (NHEJ) but is a prerequisite for homology-dependent repair processes (homologous recombination, HR, and alternative end joining, A-EJ) (Chang et al., 2017; Symington, 2016). These pathways are differentially engaged to mediate physiological DSB repair according to the cellular context, cell cycle phase, and type of break (Chang et al., 2017; Chapman et al., 2012; Scully et al., 2019). As a result, dysregulated DSB end processing can lead to unproductive or aberrant repair reactions with dramatic consequences at both cellular and systemic levels, as evidenced during repair of programmed DSBs in B lymphocytes undergoing class switch recombination (CSR) and of stochastic DNA replication-associated breaks in BRCA1-mutated cells.

Immunoglobulin (Ig) CSR is the process occurring in mature B lymphocytes that enables the formation of different Ig classes or isotypes, thus diversifying the effector component of immune responses (Methot and di Noia, 2017). At the molecular level, CSR is mediated by a deletional recombination reaction at the Ig heavy chain locus (Igh) that replaces the constant (C) gene for the basal IgM isotype with one of the downstream $C$ genes encoding a different Ig class (Yewdell and Chaudhuri, 2017). The reaction is initiated by the formations of multiple programmed DSBs at internally repetitive DNA stretches, known as switch (S) regions, preceding the recombining $C$ regions (Saha et al., 2021). Productive CSR events occur via protection of DSBs from nucleolytic resection, which enables NHEJ-mediated inter-S-region repair (Boboila et al., 2012; Saha et al., 2021). Defects in DSB end protection lead to unscheduled processing of $S$ region breaks, which combined with the close break proximity and the repetitive nature of these DNA stretches, favors local, hence unproductive, intra-S-region recombination reactions, and results in 
immunodeficiency (Boersma et al., 2015; Chapman et al., 2013; Dev et al., 2018; di Virgilio et al., 2013; Escribano-Díaz et al., 2013; Findlay et al., 2018; Ghezraoui et al., 2018; Gupta et al., 2018; Hakim et al., 2012; Ling et al., 2020; Noordermeer et al., 2018; Panchakshari et al., 2018; Reina-San-Martin et al., 2007; Xu et al., 2015; Yamane et al., 2013).

Conversely, extensive processing is essential for repair of DNA replicationassociated breaks, which employ HR as the physiological repair pathway (Scully et al., 2019; Symington, 2016). In this context, the HR protein BRCA1 specifically counteracts DSB end protection, thus enabling resection and HR (Bunting et al., 2010; Tarsounas and Sung, 2020). Absence of BRCA1 causes persistent protection of DNA replication-associated DSBs, which interferes with their physiological repair by HR (Bunting et al., 2010). As a result, cells accumulate unrepaired DSBs and aberrant NHEJ-mediated chromosome fusions know as radials (Bouwman et al., 2010; Bunting et al., 2010). The increased levels of genome instability are responsible for the lethality of BRCA1-mutated cells and mouse models (Tarsounas and Sung, 2020). Defects in DSB end protection can relieve the inhibitory brake on resection in BRCA1-mutated cells, and partially rescues HR, genome stability and viability (Bouwman et al., 2010; Bunting et al., 2010; Cao et al., 2009; Chapman et al., 2013; Dev et al., 2018; Escribano-Díaz et al., 2013; Feng et al., 2013; Findlay et al., 2018; Ghezraoui et al., 2018; Gupta et al., 2018; Noordermeer et al., 2018; Xu et al., 2015; Zimmermann et al., 2013).

Recently, pathways that counteract the nucleolytic degradation of nascent DNA at replication forks have proven to be crucial to maintain genome stability under conditions of replication stress (Pasero and Vindigni, 2017; Rickman and Smogorzewska, 2019; Schlacher et al., 2011). Replication fork reversal is the mechanism that converts a classic three-way junction fork into a four-way junction structure via the annealing of the newly synthesized complementary DNA strands and the re-annealing of the parental strands (Neelsen and Lopes, 2015). This process, which results in the formation of a fourth regressed arm, appears to have a stabilizing effect on forks stalled as a consequence of DNA replication stress (Liao et al., 2018). However, reversed 
forks can act as the entry point for various DNA nucleases, and unrestrained processing of the newly replicated DNA in the absence of protective factors leads to accumulation of DNA breaks and hyper-sensitivity to replication stress-inducing agents (Cortez, 2015; Neelsen and Lopes, 2015).

The multifunctional protein RIF1 has emerged as a key regulator of DNA processing. During repair of DSBs, RIF1 acts in the 53BP1/Shieldin-mediated cascade that inhibits resection of DNA ends (Chapman et al., 2013; di Virgilio et al., 2013; Escribano-Díaz et al., 2013; Feng et al., 2013; Zimmermann et al., 2013). As a consequence, ablation of RIF1 in mature B cells severely impairs NHEJ-repair of CSR DSBs, and leads to immunodeficiency in mouse models (Chapman et al., 2013; di Virgilio et al., 2013; Escribano-Díaz et al., 2013). Conversely, deletion of RIF1 in BRCA1-deficient cells partially restores resection and HR-dependent repair of DNA replication-associated breaks, and reduces genome instability and cell lethality of this genetic background (Chapman et al., 2013; Escribano-Díaz et al., 2013; Feng et al., 2013; Zimmermann et al., 2013). Furthermore, recent studies have uncovered a DNA protective role of RIF1 during replication stress (Chaudhuri et al., 2016; Garzón et al., 2019; Mukherjee et al., 2019). RIF1 is recruited to stalled DNA replication forks and protects newly synthesized DNA from processing by the DNA2 nuclease (Garzón et al., 2019; Mukherjee et al., 2019). Loss of RIF1 leads to increased degradation of nascent DNA at reversed forks, exposure of under-replicated DNA and genome instability (Chaudhuri et al., 2016; Garzón et al., 2019; Mukherjee et al., 2019).

Despite the multiple contributions of RIF1 in the regulation of DNA processing and the consequences on the preservation of genome integrity, very little is known about the post-translational control of RIF1 activities in these contexts. Furthermore, although the DSB resection inhibitory function of RIF1 has been the objective of extensive investigation, little information is available about how its DNA replication fork protective role is regulated. In this study, we report the identification of a cluster of conserved SQ motifs within mammalian RIF1 that is phosphorylated in actively proliferating $B$ lymphocytes. Abrogation of these phosphorylation events does not affect RIF1's ability to inhibit DSB 
bioRxiv preprint doi: https://doi.org/10.1101/2021.11.04.467328; this version posted November $6,2021$. The copyright holder for this

preprint (which was not certified by peer review) is the author/funder, who has granted bioRxiv a license to display the preprint in perpetuity. It is made available under aCC-BY 4.0 International license. 


\section{Results}

A conserved cluster of $S Q$ sites in RIF1 intrinsically disordered region is phosphorylated in activated $B$ cells

RIF1 is a large protein of almost 2500 amino acids in mammalian cells (Table S1) with no known enzymatic activity. While information about RIF1 structural organization is limited, analyses of RIF1 homologs across species identified two motifs that are highly conserved from yeast to mammals: the N-terminal Huntingtin, Elongation factor $3, \underline{A}$ subunit of protein phosphatase $2 \mathrm{~A}$, and Ior1 (HEAT) repeats, and the SILK-RVxF motif, whose sequence location shifted from the $\mathrm{N}$-terminus to the $\mathrm{C}$-terminal end during the evolution of unicellular to multicellular organisms (Fig. 1A) (Sreesankar et al., 2012; Xu et al., 2010). In vertebrates, RIF1 also exhibits a conserved C-terminal domain with a tripartite structure (Fig. 1A) (Xu et al., 2010). The region spanning between these $\mathrm{N}$ - and $\mathrm{C}$-terminal motifs is poorly conserved and is characterized by a high degree of intrinsic disorder (Fig. 1A). Additionally, RIF1 contains multiple serine-glutamine/threonine-glutamine (SQ/TQ) motifs, which are consensus sites for phosphorylation by the DNA damage response kinases ATM and ATR (Blackford and Jackson, 2017) (Fig. 1A and Table S2).

To identify post-translational modifications (PTMs) that modulate RIF1 functions in the maintenance of genome stability, we took advantage of the Isotopic Differentiation of Interactions as Random or Targeted (I-DIRT) experiment that we recently performed to define RIF1 interactome in mature $B$ lymphocytes activated to differentiate ex vivo (Delgado-Benito et al., 2018). In addition to experiencing programmed DSB formation and repair during $\mathrm{lg}$ CSR, activated $B$ cells undergo a proliferative burst that renders them susceptible to DNA replication stress and damage (Fig. 1B). Furthermore, activated $B$ cells express considerably higher levels of RIF1 than their mouse embryonic fibroblasts (MEFs) counterparts (Fig. 1C). The I-DIRT approach employed primary cultures of splenocytes from mice harboring a FLAG-2xHAtagged version of RIF1 (RIF1FH, (Cornacchia et al., 2012; Delgado-Benito et al., 2018)), which is expressed at physiological levels (Fig. 1C and (DelgadoBenito et al., 2018)). For the RIF1 I-DIRT experiment, activated splenocytes 
cultures were also irradiated, which would simultaneously increase the level and broaden the range of DNA damage-induced PTMs (Fig. 1D, (DelgadoBenito et al., 2018)). Furthermore, $\alpha$ FLAG-mediated pulldown of RIF1 was performed under conditions that preserved bona fide protein interactions and native complex formation (Fig. 1D, (Delgado-Benito et al., 2018)). The RIF1 IDIRT experiment generated a list of high confidence interactor candidates with functions ranging from DSB repair to transcriptional regulation of gene expression (Fig. 1D and (Delgado-Benito et al., 2018)). Furthermore, a differential filtering criteria analysis uncovered an extended network of factors contributing to DNA replication initiation, elongation and fork protection (Fig. 1D). Altogether, these observations indicate that activated $B$ cells provide an ideal model system to probe for RIF1 multiple biological functions and prompted us to re-evaluate RIF1 I-DIRT datasets for potentially relevant PTMs.

Analysis of post-translationally modified RIF1 peptides from different I-DIRT preparations revealed phosphorylation to be the predominant PTM, with the majority of phospho-residues being serines followed by either a proline or a glutamic acid (SP or SE) (data not shown). Among all SQ/TQ motifs present in mouse RIF1, $S^{1387} Q, S^{1416} Q$, and $S^{1528} Q$ were reproducibly found to be phosphorylated across independent RIF1 I-DIRT datasets (Fig. 1, E and F). These SQ motifs exhibit a relatively high degree of conservation across species (Table $S 1$ and $S 2$ ). More interestingly, $S^{1387} Q, S^{1416} Q$, and $S^{1528} Q$ $\left(S^{1403} \mathrm{Q}, S^{1431} \mathrm{Q}\right.$, and $S^{1542} \mathrm{Q}$ in hRIF1) are located in close proximity to each other and form a defined cluster of $S Q$ sites in the intrinsically disordered region (IDR) of both mouse and human RIF1 (IDR-CII SQs) (Fig. 1G).

We concluded that in activated B lymphocytes, RIF1 is phosphorylated at a conserved cluster of SQ motifs within its IDR. 
$A$
$m$
$m$
0
0
0
0
0
0
0
0
0
0

B

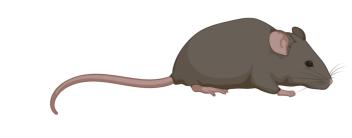

Primary B cells

Splenocytes

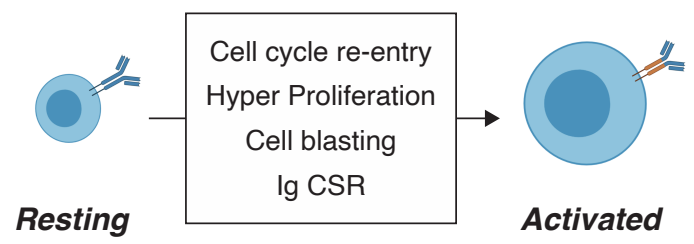

D

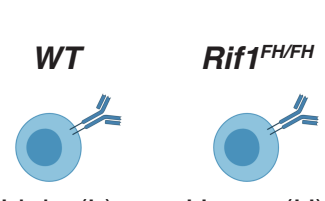

Light (L) Heavy (H)

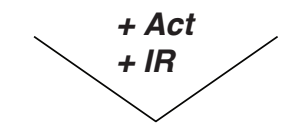

RIF1 IP \& LC-MS/MS

$\mathrm{H} /(\mathrm{H}+\mathrm{L})>0.5$

Specific

RIF1 interactors

G
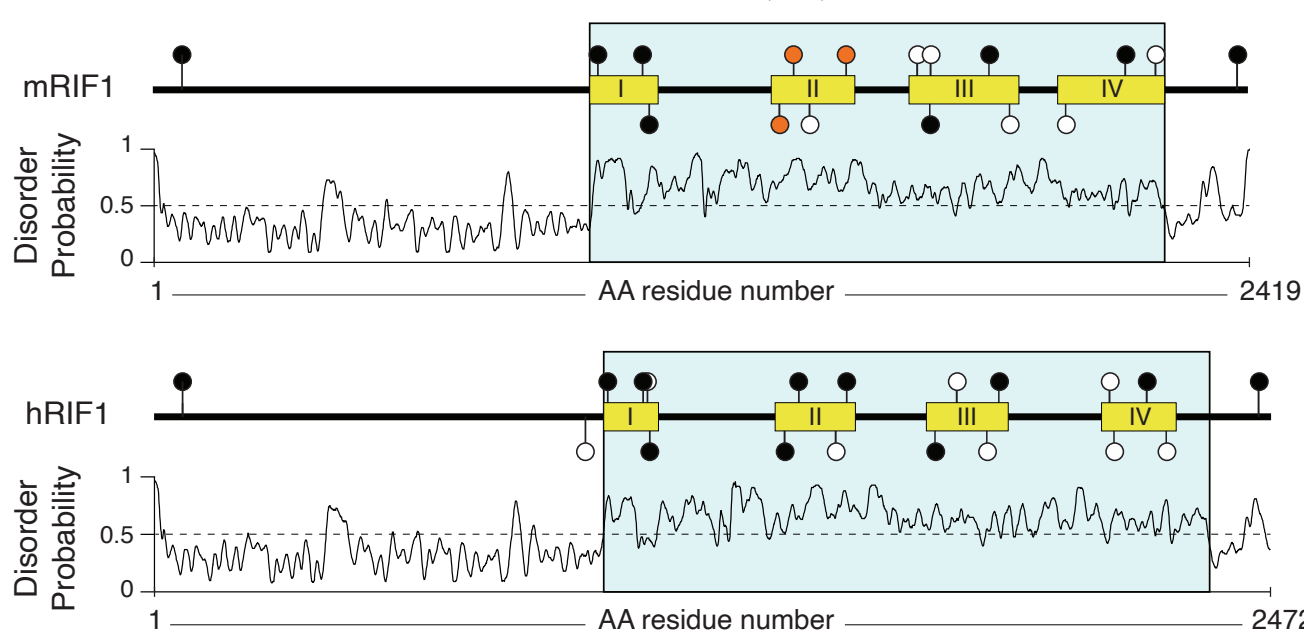

C

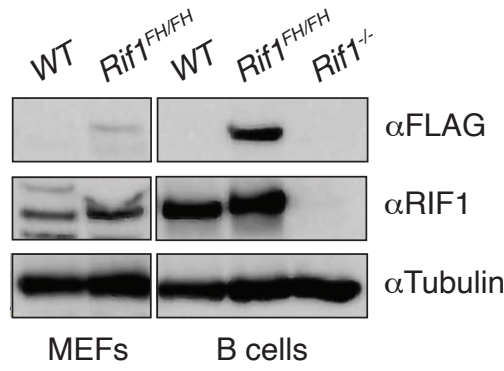

E

E $\quad \mathrm{pSQ}$ motif $\quad \mathrm{MS} / \mathrm{MS}$ spectra

\begin{tabular}{lc}
\hline $\mathrm{S} 1387 \mathrm{Q}$ & 5 \\
$\mathrm{~S} 1416 \mathrm{Q}$ & 4 \\
$\mathrm{~S} 1528 \mathrm{Q}$ & 12
\end{tabular}

F S1387Q
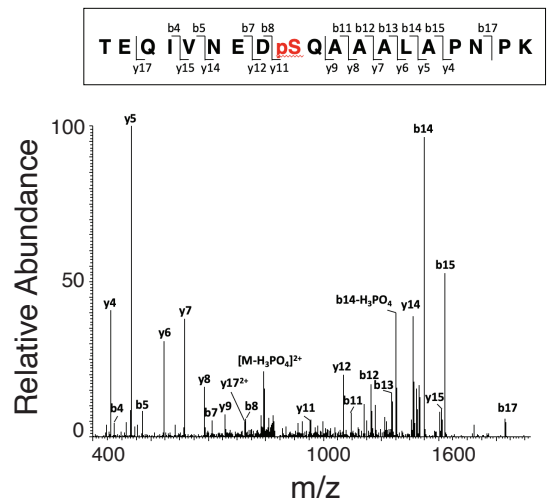

S1416Q

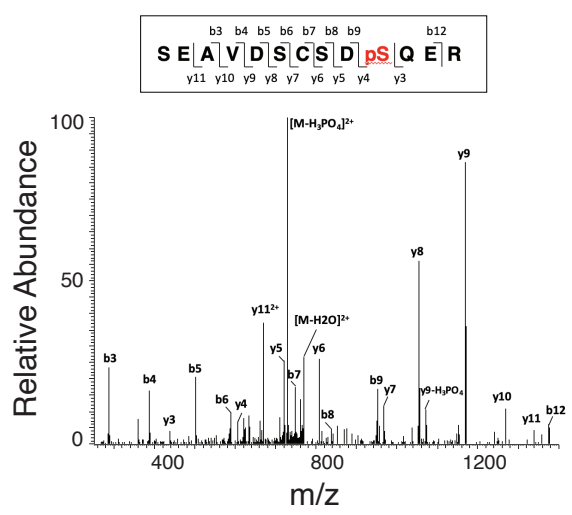

S1528Q

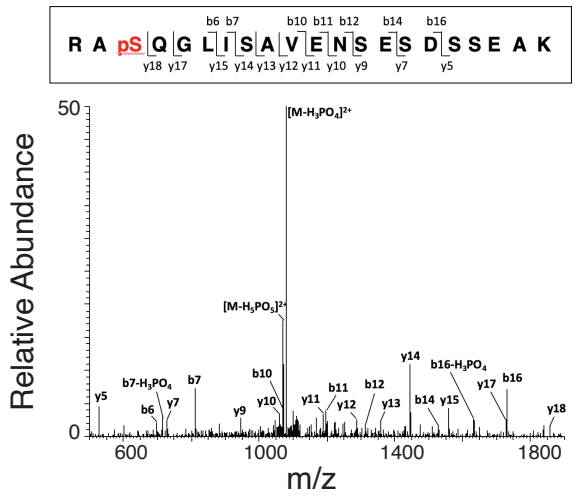


Figure 1. A conserved cluster of SQ motifs within RIF1 intrinsically disordered region is phosphorylated in activated $B$ lymphocytes. (A) Top: Schematic representation of mammalian RIF1 domains and motifs. The scheme refers to the canonical sequence for mouse RIF1 (mRIF1, isoform 1, 2419 amino acids, UniProt entry Q6PR54-1). Filled and empty circle symbols represent conserved and non-conserved SQ/TQ motifs, respectively, between mRIF1 and human RIF1 (hRIF1, isoform 1, 2472 amino acids, UniProt entry Q5UIP0-1) (see also Tables S1 and S2). CTD: carboxyl-terminal domain. Bottom: Disorder profile plot of mRIF1 as determined by Protein Disorder prediction System (PrDOS). (B) Schematic representation of key cellular changes and processes induced by the activation of mature B lymphocytes. Ig CSR: immunoglobulin class switch recombination. (C) Western blot analysis of whole cell extracts from MEFs and primary B cells derived from mice of the indicated genotypes. For each depicted antibody staining, the left and right blots represent non-contiguous portions of the same gel and film exposure. Rif1 ${ }^{-}:$Rif1 $1^{F / F} C d 19^{C r e /}+$. (D) Left: Schematic representation of RIF1 I-DIRT in primary cultures of $B$ cells. Light $(L)$ : light media; Heavy $(H)$ : heavy media; Act: Activation; IR: ionizing radiation; LC-MS/MS: liquid chromatographytandem mass spectrometry. Right: Graph depicting the distribution of identified RIF1 I-DIRT proteins as a function of their $\mathrm{H} /(\mathrm{H}+\mathrm{L})$ ratio and posterior error probability (PEP) (data from (Delgado-Benito et al., 2018)). Only proteins with posterior error probability (PEP) $\leq 10^{-4}$ were included in the graph. SD: standard deviation units $(0.10)$ from the mean of the distribution (0.49); Count: number of peptides identified per protein. (E) Number of MS/MS spectra identified for the indicated phosphorylated SQ (pSQ) motifcontaining peptides in different RIF1 I-DIRT preparations. (F) Representative MS/MS spectra of the RIF1 peptides encompassing phosphorylated residues $\mathrm{S}^{1387}, \mathrm{~S}^{1416}$, and $\mathrm{S}^{1528}$. (G) Schematic representation of $\mathrm{SQ} / \mathrm{TQ}$ motif clusters in the intrinsically disordered regions (IDRs) of mouse and human RIF1, which were defined by the PrDOS disorder profile plots (Ishida and Kinoshita, 2007). Orange filled symbols represent the conserved $S^{1387}, S^{1416}$, and $S^{1528}$ residues identified as phosphorylated SQ motifs in mRIF1. 
Table S1. List of RIF1 protein homologs across representative species from the Animalia and Fungi kingdoms.

\begin{tabular}{|c|c|c|c|c|c|c|c|c|c|}
\hline Kingdom & $\begin{array}{c}\text { Phylum } \\
\text { (Animalia) / } \\
\text { Division (Fungi) }\end{array}$ & Class & Infraclass & $\begin{array}{c}\text { Clade/ } \\
\text { Superorder }\end{array}$ & Order & $\begin{array}{l}\text { Genus \& } \\
\text { Species }\end{array}$ & $\begin{array}{l}\text { Common } \\
\text { name }\end{array}$ & $\begin{array}{c}\text { RIF1 } \\
\text { UniProt ID }\end{array}$ & $\begin{array}{l}\mathbf{N}^{\circ} \\
\mathbf{A A}^{*}\end{array}$ \\
\hline \multirow[t]{16}{*}{ Animalia } & \multirow{15}{*}{$\begin{array}{l}\text { Chordata } \\
\text { (Vertebrates) }\end{array}$} & \multirow[t]{11}{*}{ Mammalia } & \multirow[t]{9}{*}{ Placentalia } & \multirow[t]{5}{*}{ Euarchontoglires } & \multirow[t]{3}{*}{ Primates } & Homo sapiens & Human & Q5UIP0-1 & 2472 \\
\hline & & & & & & Pan troglodytes & Chimpanzee & A0A6D2Y1B4 & 2473 \\
\hline & & & & & & $\begin{array}{l}\text { Callithrix } \\
\text { jacchus }\end{array}$ & Marmoset & F7I9U7 & 2463 \\
\hline & & & & & Rodentia & Mus musculus & Mouse & Q6PR54-1 & 2419 \\
\hline & & & & & Lagomorpha & $\begin{array}{l}\text { Oryctolagus } \\
\text { cuniculus }\end{array}$ & Rabbit & G1TYW6-1 & 2455 \\
\hline & & & & \multirow[t]{2}{*}{ Laurasiatheria } & Artiodactyla & Bos taurus & Cow & E1BCK1 & 2313 \\
\hline & & & & & Perissodactyla & Equus caballus & Horse & A0A3Q2H5U1 & 2476 \\
\hline & & & & Afrotheria & Proboscidea & $\begin{array}{l}\text { Loxodonta } \\
\text { africana }\end{array}$ & Elephant & G3T4D9 & 2441 \\
\hline & & & & Xenarthra & \multicolumn{4}{|c|}{ Not included in the analysis. } & \\
\hline & & & Marsupialia & l & Didelphimorphia & $\begin{array}{l}\text { Monodelphis } \\
\text { domestica }\end{array}$ & Opossum & K7E160 & 2408 \\
\hline & & & Monotremata & I & Monotremata & $\begin{array}{l}\text { Ornithorhynchus } \\
\text { anatinus }\end{array}$ & Platypus & F7BUB6 & 2455 \\
\hline & & Aves (Birds) & 1 & 1 & Galliformes & Gallus gallus & Chicken & E1C2U2-1 & 2326 \\
\hline & & Amphibia & I & 1 & Anura & Xenopus laevis & $\begin{array}{l}\text { Xenopus or } \\
\text { African } \\
\text { clawed frog }\end{array}$ & I6N3H5 & 2327 \\
\hline & & $\begin{array}{l}\text { Actinopterygii } \\
\text { (bony fishes) }\end{array}$ & I & I & Cypriniformes & Danio rerio & Zebrafish & B0UY57 & 2392 \\
\hline & & $\begin{array}{l}\text { Chondrichthyes } \\
\text { (cartilaginous fishes) }\end{array}$ & I & I & Chimaeriformes & $\begin{array}{l}\text { Callorhinchus } \\
\text { milii }\end{array}$ & Shark & A0A4W3IQ02 & 2254 \\
\hline & $\begin{array}{l}\text { Arthropoda } \\
\text { (Invertebrates) }\end{array}$ & Insecta & I & I & Diptera & $\begin{array}{l}\text { Drosophila } \\
\text { melanogaster }\end{array}$ & $\begin{array}{l}\text { Drosophila } \\
\text { or } \\
\text { Fruit fly }\end{array}$ & Q9XZ34 & 1416 \\
\hline \multirow[t]{2}{*}{ Fungi } & \multirow{2}{*}{$\begin{array}{l}\text { Ascomycota } \\
\text { (Lower } \\
\text { eukaryotes) }\end{array}$} & Saccharomycetes & I & 1 & Saccharomycetales & $\begin{array}{l}\text { Saccharomyces } \\
\text { cerevisiae }\end{array}$ & $\begin{array}{l}\text { (Baker's) } \\
\text { yeast }\end{array}$ & P29539 & 1916 \\
\hline & & Schizosaccharomycetes & I & 1 & Schizosaccharomycetales & $\begin{array}{l}\text { Schizosaccharo } \\
\text { myces pombe }\end{array}$ & Fission yeast & Q96UP3 & 1400 \\
\hline
\end{tabular}

${ }^{*} \mathrm{~A} A=$ amino acids 
Table S2. Alignment of peptides containing SQ/TQ motifs conserved between mouse and human RIF1 proteins across representative species from the Animalia and Fungi kingdoms.

\begin{tabular}{|c|c|c|c|c|c|c|c|c|c|c|}
\hline mRIF1 SQ & $\mathrm{S} 66 \mathrm{Q}$ & S986Q & S1086Q-S1096Q & $\mathrm{S} 1387 \mathrm{Q}$ & $\mathrm{S} 1416 \mathrm{Q}$ & $\mathrm{S} 1528 \mathrm{Q}$ & $\mathrm{S} 1713 \mathrm{Q}$ & S1842Q & $\mathrm{S} 2138 \mathrm{Q}$ & S2387Q \\
\hline hRIF1 SQ & S66Q & S989Q & S1089Q-S1098Q & $S 1403 Q$ & $\mathrm{~S} 1431 \mathrm{Q}$ & S1542Q & S1739Q & S1873Q & S2189Q & S2439Q \\
\hline Mouse & KAHISSQNSELS & ESTENSQLNVKI & NNLDASQDTLFSAQFSQEESME & IVNEDSQAAALA & DSCSDSQERESG & QTRRASQGLISA & CCGEKSQS--QEKS & ECKDISQKQLSE & RGLKRS-QEDEI- & YSYTGSQLFEMH \\
\hline Human & KTHISSQNSELS & DGTENSQLNVKI & NNLDVSQDTLF-TQYSQEEPME & MVNEDSQVQITP & ESTTESQDKENS & QTRRASQGLLSS & CCGEKSQP--QEKS & DSKNVSQE--SL & RGLKRS-QEDEIS & HNYSGSQLFEMH \\
\hline Chimpanzee & KTHISSQNSELS & DGTENSQLNVKI & NNLDVSQDTLF-TQYSQEEPME & MVNEDSQVQITP & ESTTESQDKENN & QTRRASQGLLSS & CCGEKSQP--QEKS & DSKNVSQE--SL & RGLKRS-QEDEIS & HNYSGSQLFEMH \\
\hline Marmoset & KTHISSQNSELS & DGAENSQFNVKI & NNLDVSQDTLF-TQYSQEESME & MVNEDSQSQITA & ESTTDSQDKENN & QTRRASQGLLSS & CCGEKPQP--QEK- & DLENASQE--SL & RGLKRS-QEDEIS & HNYSGSQLFEMH \\
\hline Rabbit & RTHISSPNLELS & DATENSQLNLKI & NNLDVSQDTFLSSQYSQEESME & MVNEDSQVQITP & ESTTDSQDKENN & QTRRASQGLLSS & CCGEKSQS--QEKS & DPKNIQQECSPF & RGLKRP-QEDENS & HNYSGNQLFEMH \\
\hline Cow & ----- & DMTENSQLNMKI & NNLDVSQDTLF-SQYSQEESME & TVNEDSHIQVTP & EPTTDSQDKENN & QTRRASQGLLSS & CCGEKSQS--QEKS & VSKDISLKCFSL & RGLKRP-QEDEIS & YNYSGSQLFEMH \\
\hline Horse & KTHISSQNSELS & EGRENSQLNMKI & NNLDVSQDALY-SQYGQEESME & MINEDSHVQITP & EPTTESQDKENN & QTRRASQGLLSS & CCGEKSQP--QEKS & DSKDISLECSTF & RGLKRPLQEDEIS & HNYSGSQLFEMH \\
\hline Opossum & KTHISSQNSELN & EGTENSQLDAKI & NNLDISQDSES--YHTQEETME & QIPNDDSHIQVS & EGTPDRQDKENG & QTRRASLGLLSS & $\begin{array}{l}\text { CCGEKSKL--REKF } \\
\end{array}$ & SINNSQ---DSF & RGIKRQ-QEDEAS & HNYSGSQLFEMQ \\
\hline Platypus & QVHISHQNSELN & EPTENTQLEAKI & NNLDVSQDTALFSQYSQEESME & MSNEDSQGPQIA & ECATGSQDKENS & QTRRASQGLLSS & CCGEKSQS--QEKS & NDDDSL---DPL & RGIKRP-QEDETP & HQYSGSQLFEMQ \\
\hline Chicken & KAHISSENSELS & DEAENSQWDAKL & NNLDSSQDTTLFSQY $\underline{\text { TQSQEDS }}$ & VMGDGSQGPHAS & EMAAGSQDKEDG & HTRRSSQGLLSS & CCSKRVKQ--QTS- & ------------- & RGVKRH-HEDDSL & RSYPGSRLFEMQ \\
\hline Lizard & ------------- & $\begin{array}{l}\text { DSVSIRVWHWLY } \\
\end{array}$ & ------------------------- & TISNVGQSPQVS & EGASGSPDKENS & QTRRTSQGLLIS & SSPEKS-S--ETKG & ------------- & RGVKRQ-KEEDSP & LNYSVSELFEMQ \\
\hline Xenopu & KAHISNQNSDLS & ENMDNSQLEAKI & NNLDASQDTTLFTQYSQSQDNS & ANNDTSQIQQAT & DGVKSIADKGQK & QTRRSSQGLVLA & CCGKASNN--KEST & ETKTVAAPEETM & KGVKRQ-QENDSP & CKYSASQLFDMQ \\
\hline Zebrafish & $\begin{array}{l}\text { LVHISSENEELC } \\
\end{array}$ & YMSESSQLEPQI & NNLDASMDTTVFSQYTQSQSQEES & ANKDLSQTELSP & TQLEESTEKETN & RTRRS-RGLLS- & $\begin{array}{l}\text { CFSNNRDVFSQDSD } \\
\end{array}$ & ------------- & KGQKRA-CEEETP & SQHSASQLGLMH \\
\hline Shark & KGHISSSNSEVG & KYSEHSQIDTKI & NNLDVSQDSHLFSQY $\underline{\text { TQSQDSS }}$ & QDEQNEQTPNTP & TGQAGSQRKKKG & QTRRSSQGISQV & CCKGSTKQ--KRKS & KV-ATSAPCDKT & KGIKRP-SENESP & NEYSGSQLFTMH \\
\hline Drosop & ------------- & ------------- & NDMSQSQDSASIKPWTPKKVVI & GTDHTSTPIQAP & KLRCESLDDVTL & ------------ & SCRNGLLA--QVPE & ------------- & --------------- & ------------- \\
\hline $\begin{array}{l}\text { Fission } \\
\text { yeast }\end{array}$ & LSDRCSNNSEGS & NHQSSEKMSDIL & KNKRQKGDVKKIDETK-NEATD & ----- & ---------- & ------------ & --------- & ------------ & --- & -1 \\
\hline
\end{tabular}

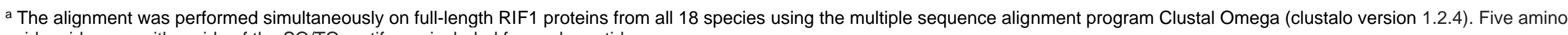
acid residues on either side of the SQ/TQ motifs are included for each peptide.

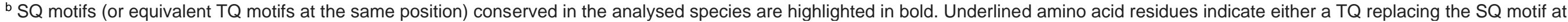

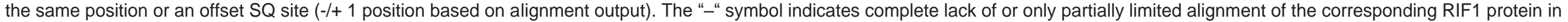
that region.

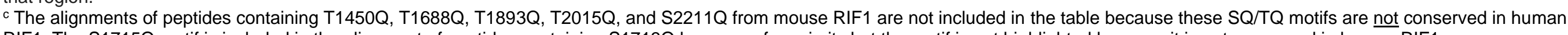

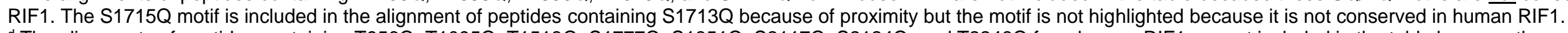

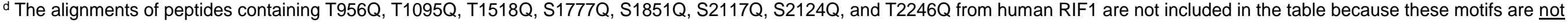
conserved in mouse RIF1. 


\section{A genetic engineering-amenable $B$ cell model system for the} assessment of DSB end protection outcomes

Phosphorylation of residues within IDRs has been reported to affect protein functions in a variety of cellular contexts (Bah and Forman-Kay, 2016; Wright and Dyson, 2015). Therefore, we decided to assess the contribution of the IDR-CII SQ phosphorylation to the regulation of RIF1 activities in DNA repair. RIF1 inhibits resection of DSBs downstream 53BP1 during both aberrant repair of DNA replication DSBs in the absence of BRCA1 and physiological end joining of CSR breaks in G1 in B cells (Chapman et al., 2013; di Virgilio et al., 2013; Escribano-Díaz et al., 2013; Feng et al., 2013; Zimmermann et al., 2013). Therefore, to determine if phosphorylation of the IDR-CII modulates RIF1 role in DSB end protection, we monitored both types of repair in cells expressing phospho-mutant RIF1.

\section{To assess for aberrant (radial chromosome formation) and physiological} (CSR) repair events in the same cellular context, we opted to perform our analysis in HR-deficient, yet CSR-proficient, $\mathrm{CH} 12$ cells bearing hypomorphic Brca1 mutations (Fig. 2A). $\mathrm{CH} 12$ is a well-characterized mouse $\mathrm{B}$ cell lymphoma line that recapitulates the molecular mechanism and regulation of CSR (Nakamura et al., 1996). Furthermore, $\mathrm{CH} 12$ cells display a stable neardiploid genome that can be easily and efficiently manipulated by somatic gene targeting (Delgado-Benito et al., 2020, 2018; Sundaravinayagam et al., 2019). These features render $\mathrm{CH} 12$ the preferred model system over $\mathrm{B}$ cells isolated from the available BRCA1-mutated mouse models, which: 1) are refractory to classic transfection methods; 2) do not allow for transduction-based reconstitution studies of large proteins like RIF1; and 3) whose primary nature precludes genetic manipulation for knock-in generation.

To generate BRCA1-mutated $\mathrm{CH} 12$ cells able to support CSR, we introduced in-frame deletions specifically within exon 11 of the Brca1 gene (Björkman et al., 2015; Bunting et al., 2010; Callen et al., 2013). Targeted deletion of Brca1 exon 11 in mice results in the expression of a splice variant (BRCA1- $\Delta 11)$ that preserves intact $\mathrm{N}$-terminal $\mathrm{RING}$ finger domain and $\mathrm{C}$-terminal $\mathrm{BRCT}$ repeats but lacks key motifs that are essential for BRCA1 functions (Evers 
and Jonkers, 2006; Xu et al., 2001, 1999). BRCA1- $\Delta 11$-expressing B cells exhibit genome instability because of impaired $\mathrm{HR}$ but undergo CSR as proficiently as WT cells (Bunting et al., 2010; Callen et al., 2013). We employed two different nickase gRNA pairs directed towards the 5 ' region of the exon (Fig. S1A). All analyzed clones bore in-frame deletions, which are indicative of internally deleted, hypomorphic BRCA1 mutants (Brca1 ${ }^{\text {mut }}$, Fig. S1B and data not shown). To functionally confirm the partial loss of BRCA1 function, we assessed the levels of chromosomal aberrations in response to treatment with the PARP inhibitor Olaparib (PARPi). PARPi increases the load of DNA replication breaks, and in BRCA1-deficient backgrounds it triggers the accumulation of chromatid breaks and radial chromosomes (Farmer et al., 2005). These aberrations are caused by the inability to engage physiological repair by HR, in part because of suppressed DSB end resection (Bouwman et al., 2010; Bunting et al., 2010). The resulting genome instability is responsible for the increased cell lethality associated with PARPi treatment in this genetic background (Farmer et al., 2005; Rottenberg et al., 2008). Analysis of metaphase spreads revealed that in contrast to control cells, PARPi-treated Brca $1^{\text {mut }} \mathrm{CH} 12$ cell lines accumulated chromatid breaks and radials with high frequency (Fig. 2B and S1C). Accordingly, all Brca ${ }^{\text {mut }}$ cell lines displayed reduced viability in the presence of PARPi compared to their wild-type counterparts (Fig. 2C). We concluded that Brca ${ }^{m u t} \mathrm{CH} 12$ cells exhibit genome instability-driven cell death following PARPi.

Deletion of DSB end protection factors in BRCA1-deficient cells releases the inhibition on DNA end resection, and partially rescues HR, genome stability, and, as a consequence, viability (Bouwman et al., 2010; Bunting et al., 2010; Cao et al., 2009; Chapman et al., 2013; Dev et al., 2018; Escribano-Díaz et al., 2013; Feng et al., 2013; Findlay et al., 2018; Ghezraoui et al., 2018; Gupta et al., 2018; Noordermeer et al., 2018; Xu et al., 2015; Zimmermann et al., 2013). Therefore, we monitored the consequences of ablating key components of the DSB end protection cascade in Brca $1^{\text {mut }} \mathrm{CH} 12$ cell lines. In bulk targeting of RIF1 as well as of the up- and downstream pathway components 53BP1 and REV7, respectively, led to a significant rescue of viability in Brca $1^{\text {mut }}$ cells (Fig. 2D). Furthermore, Brca $1^{\text {mut }}$ Rif1 ${ }^{-1-}$ clonal 
derivatives exhibited reduced levels of chromosomal aberrations and a marked increase in viability after PARPi treatment compared to Brca $1^{m u t}$ cells (Fig. S2, A to E). We concluded that $B r c a 1^{\text {mut }} \mathrm{CH} 12$ cell lines recapitulate the RIF1-dependent genome instability and cell lethality typical of BRCA1deficient backgrounds.

$\mathrm{CH} 12$ cells can be induced to undergo CSR to $\lg$ A with high efficiency after activation with $\alpha$ CD 40, IL-4 and TGF $\beta$ (CIT cocktail, (Nakamura et al., 1996)). NHEJ repair of CSR breaks in $\mathrm{CH} 12$ mimics the molecular requirements of the physiological process in primary $\mathrm{B}$ cells. Accordingly, Brca $1^{\text {mut }} \mathrm{CH} 12$ cell lines were able to undergo stimulation-dependent CSR to levels comparable to WT $\mathrm{CH} 12$ cells (Fig 2E), whereas deletion of RIF1 in these cells dramatically impaired CSR (Fig. S2F).

Altogether, these findings show that $B r c a 1^{m u t} \mathrm{CH} 12$ cell lines allow for the investigation of both outcomes of RIF1-mediated DSB end protection: aberrant repair of DNA replication-associated DSBs and physiological end joining of CSR breaks. 
A

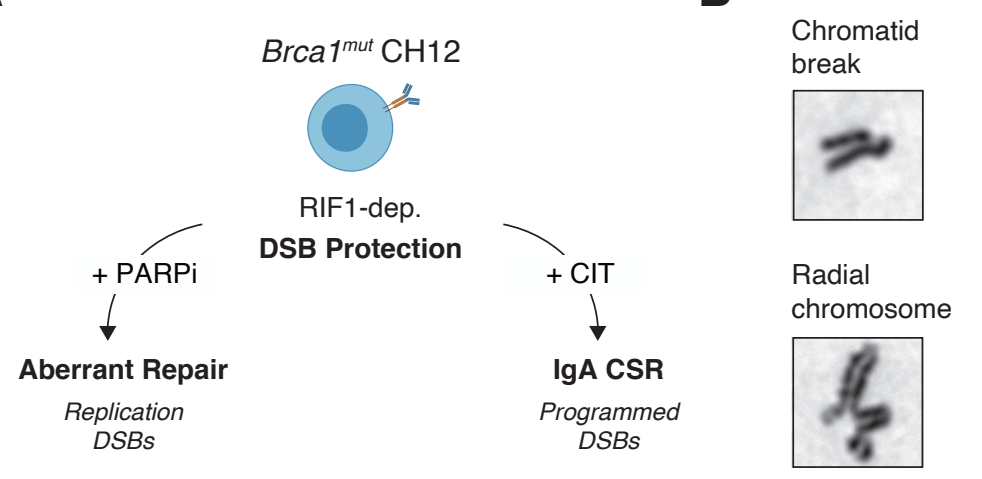

C

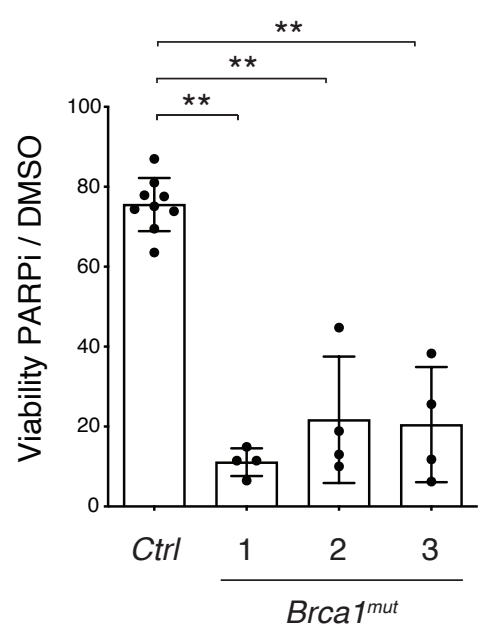

E

D
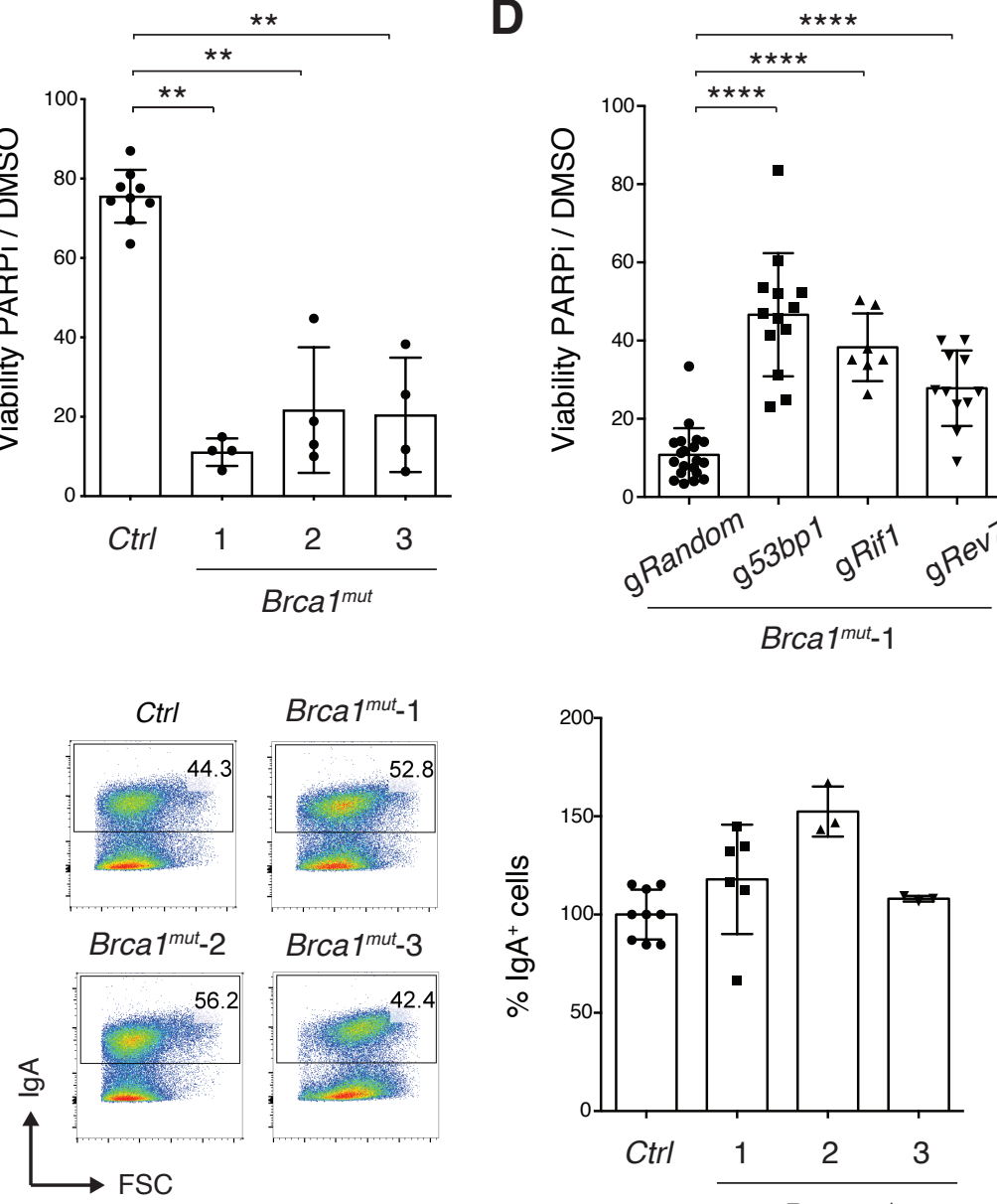

H

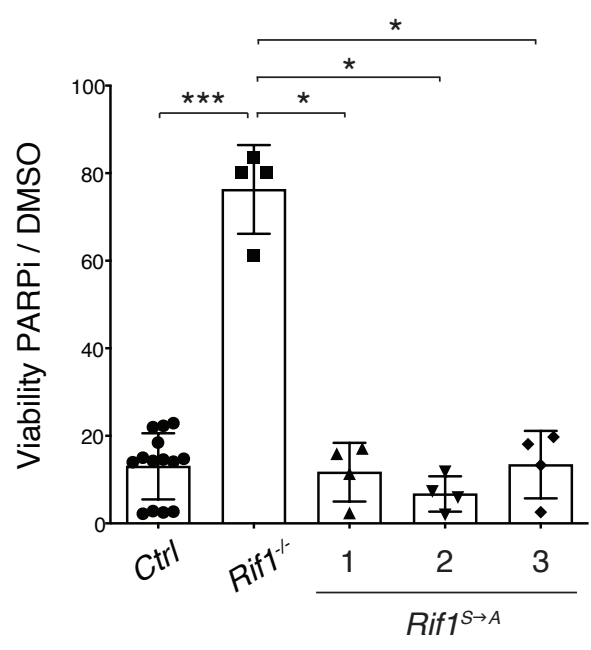

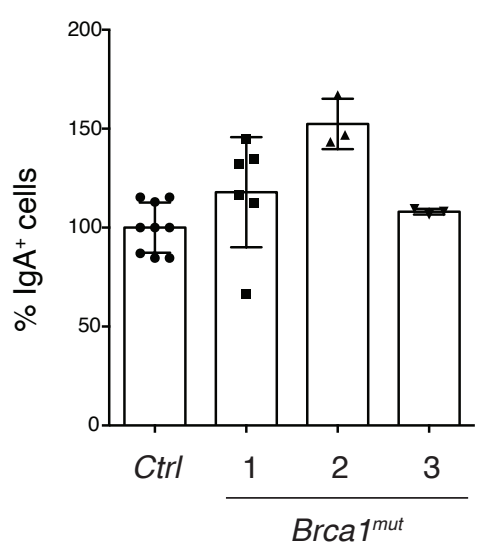

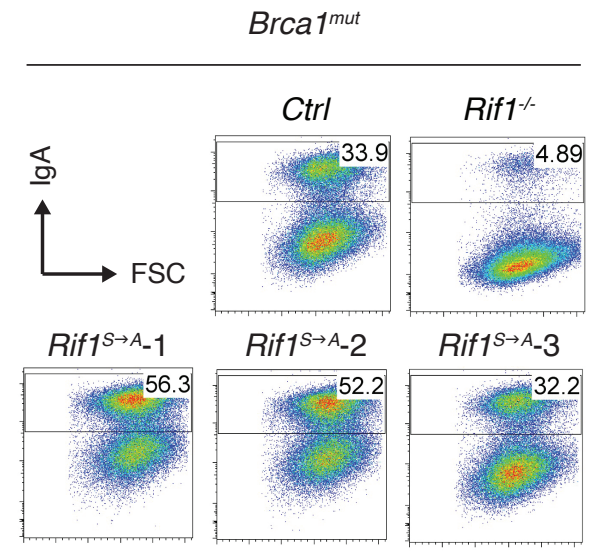

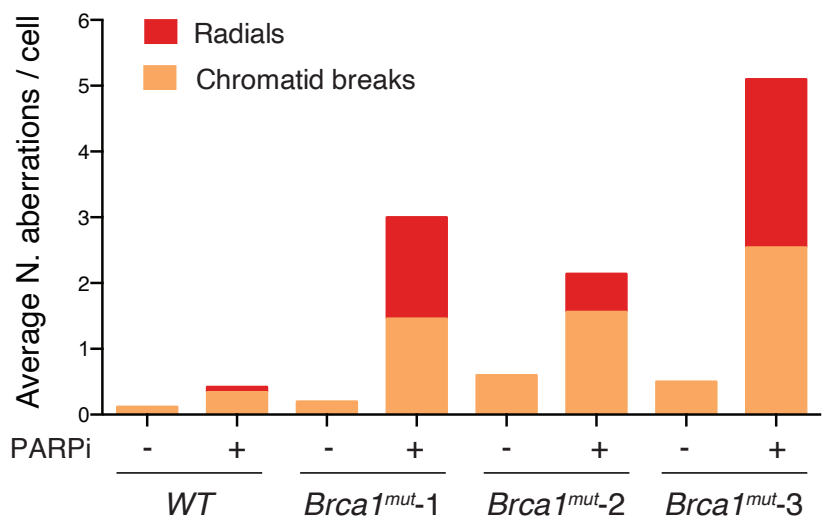

$\mathbf{F}$

RIF1WT VNEDSQAAAL----SCSDSQERES---TRRASQGLIS RIF1 ${ }^{S \rightarrow A}$ VNEDAQAAAL----SCSDAQERES---TRRAAQGLIS
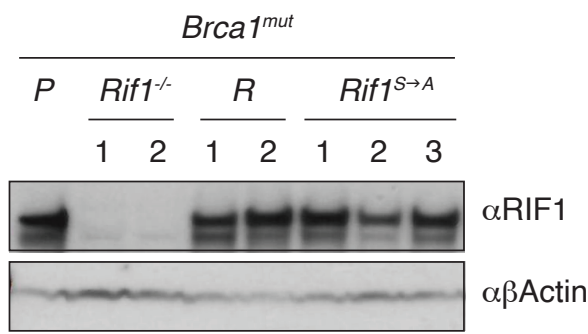

G

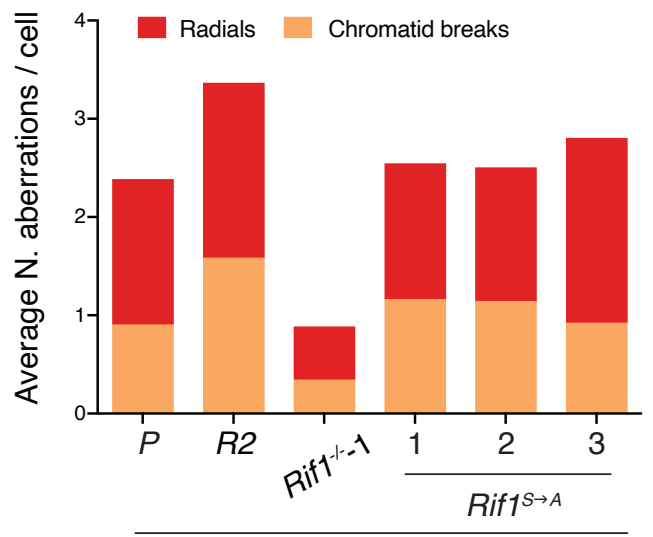

Brca1 ${ }^{\text {mut }}$

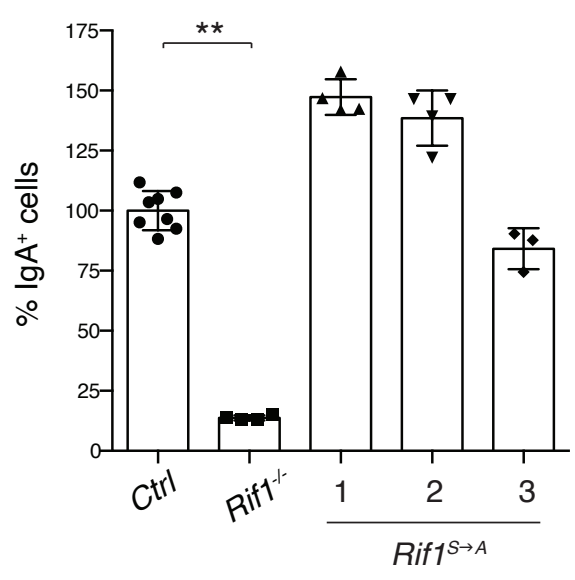


Figure 2. Phosphorylation of RIF1 at the conserved IDR-CII SQ motifs is dispensable for its roles in DSB end protection. (A) Schematic representation of BRCA1-deficient $\mathrm{CH} 12$ model system's versatility to investigate both pathological and physiological consequences of RIF1mediated DSB end protection. CIT: $\alpha \underline{\mathrm{C} D} 40, \underline{\mathrm{L}}-4$ and TGF $\beta$ B cell activation cocktail. (B) Left: Representative images of chromosomal aberrations typically associated with HR-deficiency (chromatid breaks and radial chromosomes). Right: Graph summarizing the average number of chromosomal aberrations in the parental $\mathrm{CH} 12$ cell line (WT sample) and selected Brca $1^{\text {mut }}$ clonal derivatives following $1 \mu \mathrm{M}$ PARPi treatment for $24 \mathrm{~h}(\mathrm{n}=50$ metaphases analyzed per genotype). Breakdown of the same data into actual number of aberrations per cell is shown in Fig. S1C. (C) Residual viability of Brca ${ }^{\text {mut }}$ $\mathrm{CH} 12$ cell lines after treatment with $1 \mu \mathrm{M}$ of PARPi for $72 \mathrm{~h}$. Graph summarizes four independent experiments per Brca $1^{m u t}$ clonal derivative. Residual viability was calculated as percentage of cell viability of PARPi- over DMSO-treated cultures. The control (Ctr) samples comprise parental WT $\mathrm{CH} 12$ cells and clonal cell lines generated by targeting $\mathrm{CH} 12$ cells with gRNAs against random sequences not present in the mouse genome (validated Random clones, Brca ${ }^{\text {mut }} R$ ). (D) Residual viability of Brca $1^{\text {mut }} 1$ CH12 cells nucleofected with random gRNAs (Random), or 53bp1, Rif1, and Rev7, and treated for $72 \mathrm{~h}$ with $1 \mu \mathrm{M}$ of PARPi. Graph summarizes eleven independent experiments. (E) Left: Representative flow cytometry plots measuring CSR to IgA in activated cell lines of the indicated genotype. Right: Summary graphs for at least three independent experiments per Brca $1^{m u t}$ cell line, with CSR\% levels within each experiment normalized to the average of controls (parental WT CH12 and one Random clone), which was set to 100. (F) Top: Amino acid sequence in the IDR-CII SQ region of WT and S $\rightarrow A-$ mutated RIF1 protein. Bottom: Western blot analysis of whole cell extracts from independent cells lines of the indicated genotypes (Rif $\mathrm{B}^{-/}$, control Random $R$, and Rif ${ }^{S \rightarrow A}$, all generated on the parental $(P)$ Brca $^{\text {mut }} 1$ cell line background, henceforth indicated as Brca $1^{\text {mut }}$ ). (G) Graph summarizing the average number of chromosomal aberrations in cells lines of the indicated genotypes following $1 \mu \mathrm{M}$ PARPi treatment for $24 \mathrm{~h}(\mathrm{n}=50$ metaphases analyzed per genotype). Control samples include the parental Brca1 ${ }^{m u t}-1$ cell line $(P)$ and a derivative $B r c a 1^{\text {mut }} R$ clone. $(\mathrm{H})$ Residual viability of Brca1 ${ }^{\text {mut }}$ Rif $^{S \rightarrow A}$ cell lines after treatment with $1 \mu \mathrm{M}$ of PARPi for $72 \mathrm{~h}$. Graph summarizes four independent experiments per Brca $1^{m u t} R i f 1^{S \rightarrow A}$ clonal derivative. The control (Ctr) samples comprise parental Brca1 ${ }^{\text {mut }} 1$ cells and $B r c a 1^{\text {mut }} R$ clones. (I) Left: Representative flow cytometry plots measuring CSR to $\lg A$ in activated cell lines of the indicated genotype. Right: Summary graphs for four independent experiments, with CSR\% levels within each experiment normalized to the average of controls (parental Brca $1^{\text {mut }} 1$ and one Random clone), which was set to 100 . Significance in panels $\mathrm{C}, \mathrm{D}, \mathrm{H}$, and I was calculated with the Mann-Whitney $U$ test, and error bars represent SD. ${ }^{*}=p \leq 0.05 ;{ }^{* *}=p \leq 0.01 ;{ }^{* * *}=p \leq 0.001 ;{ }^{* * \star *}=p<0.0001$. 


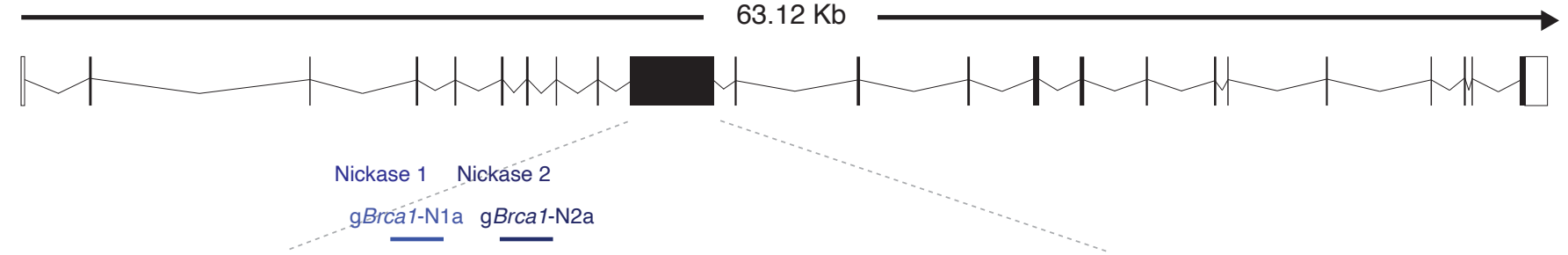

B

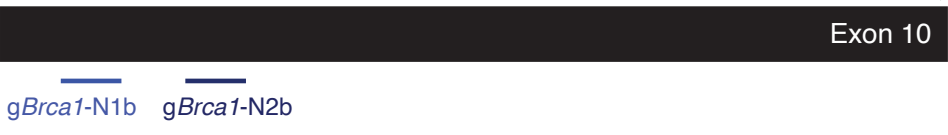

Brca 1mut-1

gBrca1-N1b

gBrca1-N1a

Indel result

Ref ATAGAGAGAAGTGGACTCACCCGCAAAGTCTGTGCCCTGAGAATTCTGGAGCTACCACCGATGTTCCTTGGATAACACTAAATAGCAGCGTTCA

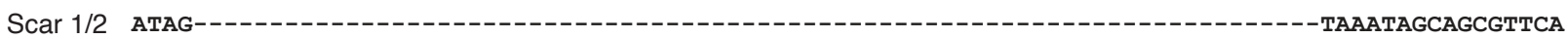

$\Delta 72$ bp $\rightarrow \Delta 24$ AA

Brca1 ${ }^{\text {mut-2 }}$ gBrca1-N2b gBrca1-N2a

Ref CTGAGAATTCTGGAGCTACCACCGATGTTCCTTGGATAACACTAAATAGCAGCGTTCAGAAAGTTAATGAGTGGTTTTCCAGAACTGGTGAAAT

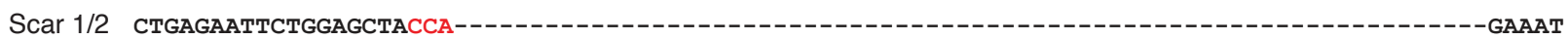
$\Delta 66 \mathrm{bp} \rightarrow \Delta 22 \mathrm{AA}$
Brca 1 ${ }^{\text {mut_-3 }}$
gBrca1-N2b
gBrca1-N2a

Ref CTGAGAATTCTGGAGCTACCACCGATGTTCCTTGGATAACACTAAATAGCAGCGTTCAGAAAGTTAATGAGTGGTTTTCCAGAACTGGTGAAAT

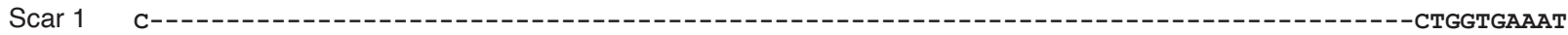

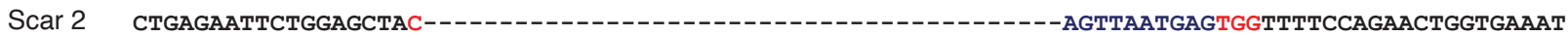

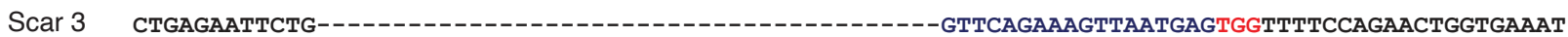

fs \& PTC

fs \& PTC

$\Delta 84 \mathrm{bp} \rightarrow \triangle 28 \mathrm{AA}$

C

$W T+\mathrm{PARPi}$

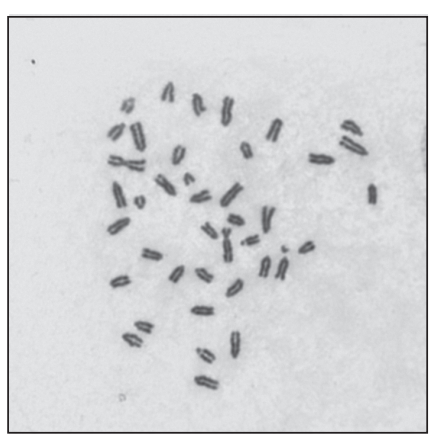

Brca1 $^{\text {mut }}$-1 + PARPi

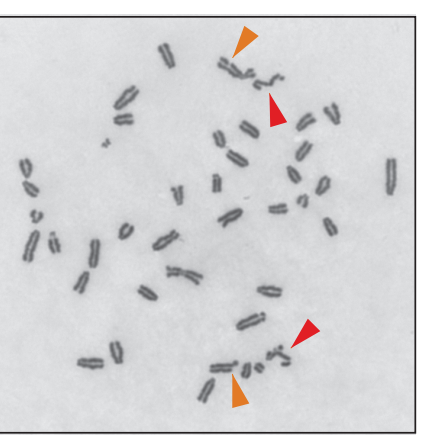

Brca 1 $_{\text {mut_2 + PARPi }}$
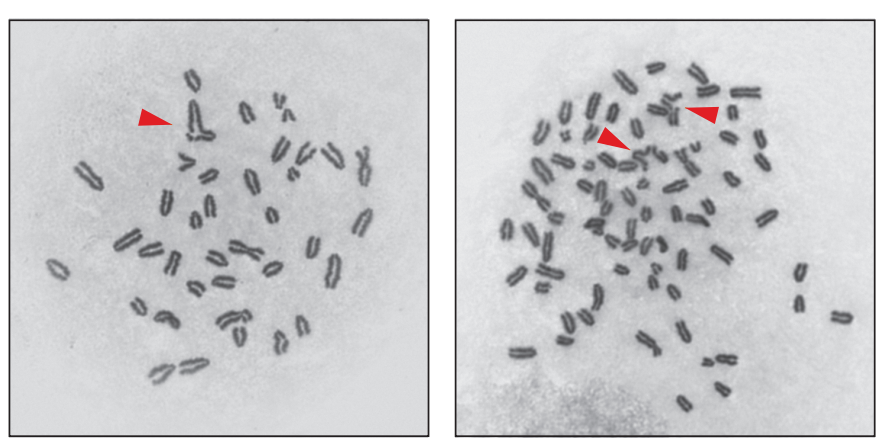

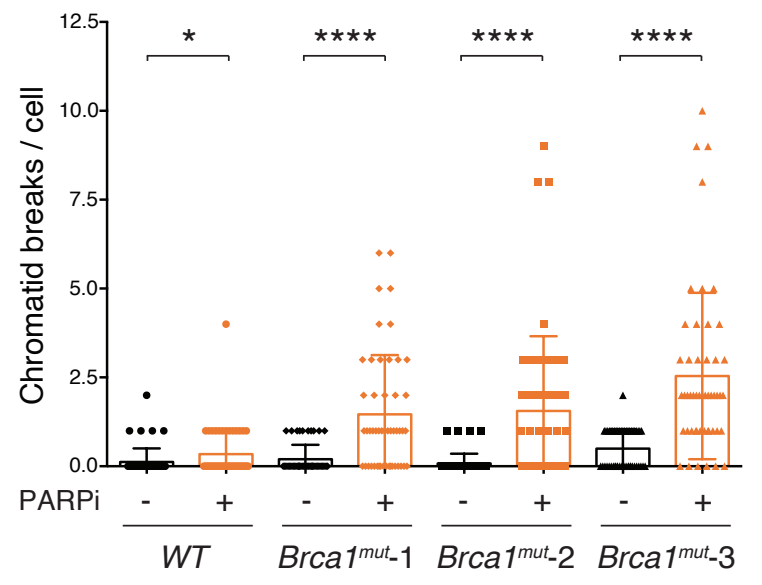

WT

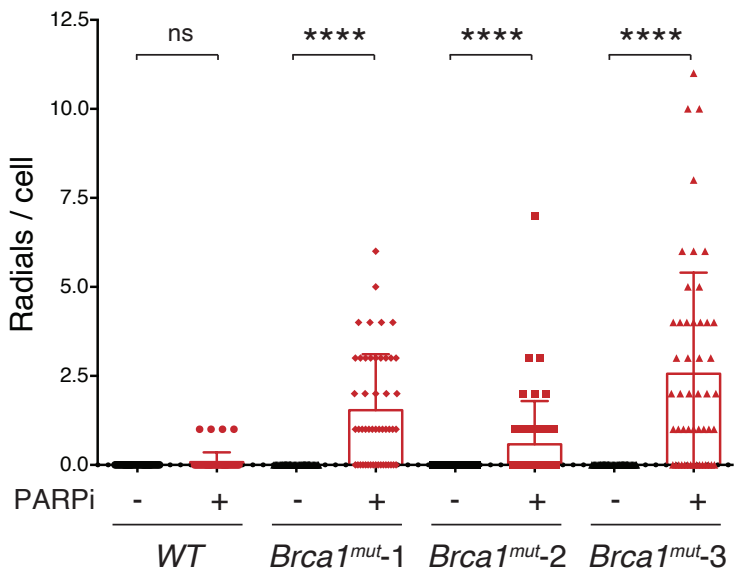


Figure S1. BRCA1-mutated $\mathrm{CH} 12$ cell lines recapitulate the genomic instability of BRCA1 deficiency. (A) Scheme of mouse Brca1 genomic locus (scheme adapted from Ensembl ENSMUST00000017290.10) and location of gRNAs used in this study. The nickase gRNA pairs are gBrca1-N1a and gBrca1-N1b for Nickase 1, and gBrca1-N2a and gBrca1-N2b for Nickase 2. Please note that the targeted exon, which is the $10^{\text {th }}$ exon in the official Ensembl Brca1-201 transcript, is commonly referred to in literature (and in the text of this manuscript) as exon 11 because of an historical misannotation of one additional exon (Evers and Jonkers, 2006; Miki et al., 1994). (B) Genomic

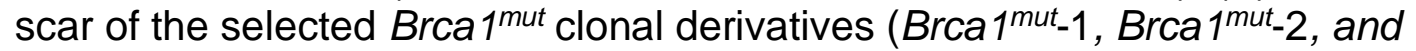
Brca1 ${ }^{\text {mut }}$-3). The expected/potential consequences at the protein level are indicated for each scar. The gRNAs employed to generate each cell line are highlighted in shades of blue with the PAM sequence in red. Note that Brca ${ }^{\text {mut }}$-1 and Brca ${ }^{\text {mut }}$-2 bear the same CRISPR scar on both alleles whereas the Brca ${ }^{\text {mut }} 3$ cell line has three genomic scars since it possesses a near-tetraploid chromosome set (see also panel $C$ ). Ref: reference sequence; Indel: insertion and/or deletion; $\Delta$ : base pairs (bp)/amino acid (AA) deletion; fs: amino acid frameshift; PTC: premature termination codon. (C) Analysis of genomic instability in Brca ${ }^{\text {mut }} \mathrm{CH} 12$ cell lines. Top: Representative metaphase spreads from parental $\mathrm{CH} 12$ cell line (WT sample) and selected Brca ${ }^{\text {mut }}$ clonal derivatives following PARPi treatment ( $1 \mu \mathrm{M}$ for $72 \mathrm{~h}$ ). Orange and red arrows indicate examples of chromatid breaks and radial chromosomes, respectively. Bottom: Summary graphs for the number of chromatid breaks and radial chromosomes per metaphase/cell $(n=50$ metaphases analyzed per genotype). Significance in panel $C$ was calculated with the Mann-Whitney $\mathrm{U}$ test, and error bars represent SD. ns = not significant; ${ }^{*}=p \leq 0.05 ;{ }^{* * *}=p<0.0001$. 

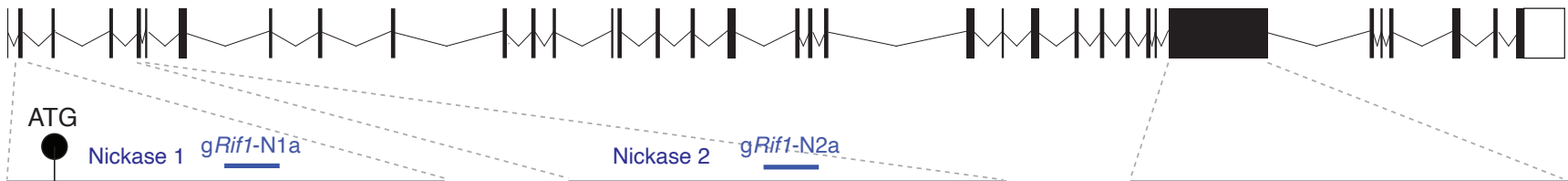

Nickase 2 gRif1-N2a

B

$$
\mathrm{g} \overline{\text { Rif1-N1b }}
$$

$\mathrm{g} \overline{\text { Rif1-N2b }}$

Brca1 $^{\text {mut }}$ Rif1 $^{-/-1}$

gRif1-N1b

gRif1-N1a

Indel result

Ref GGCCCCAGGTCGCAGCCCCCTGGAGCCGCTTCTGGAGACTTGGGAAGACCCCTCGGTGCCTCCGGGAGAGCAGACGGACGCCTACCTAACTC

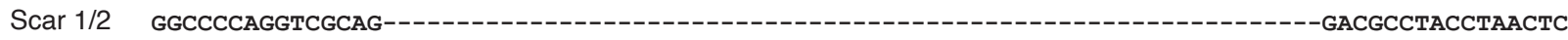

Brca ${ }^{\text {mut }}$ Rif1 ${ }^{-}-2$

gRif1-N1b

gRif1-N1a

Ref GGCCCCAGGTCGCAGCCCCCTGGAGCCGCTTCTGGAGACTTGGGAAGACCCCTCGGTGCCTCCGGGAGAGCAGACGGACGCCTACCTAACTC

Scar $1 / 2$ GGCCCCAGGTCGCAGCCCCT

-GGACGCCTACCTAACTC

C

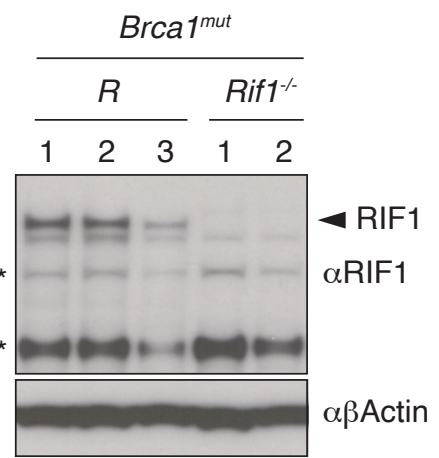

G

Rif1 locus
D Radials

Chromatid breaks

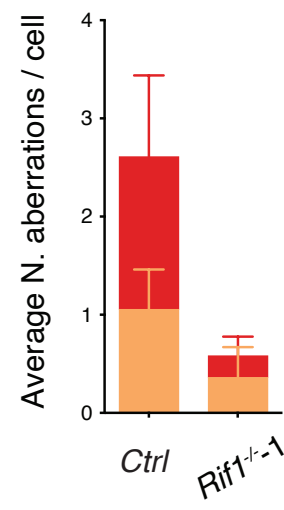

E

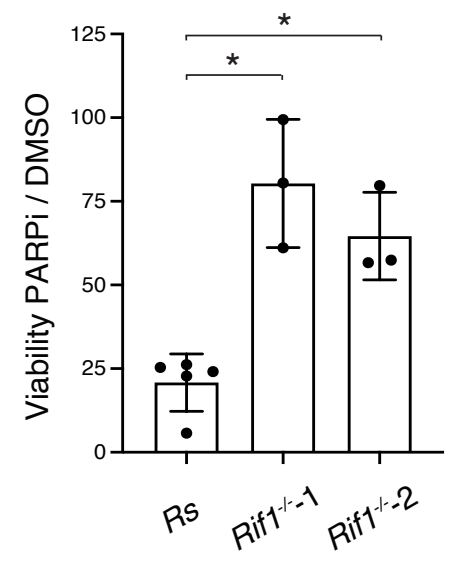

Brca $^{\text {mut }}$
F

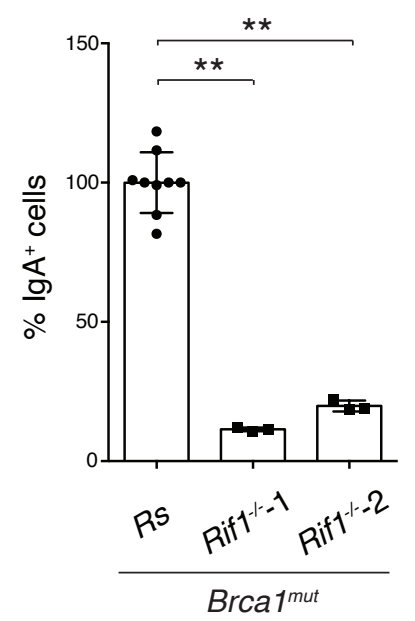

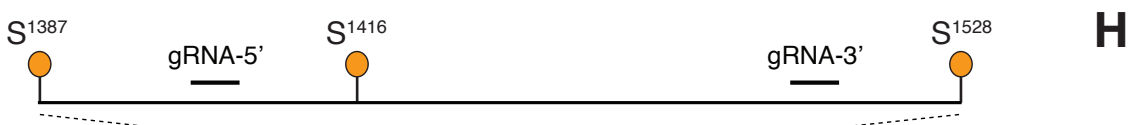
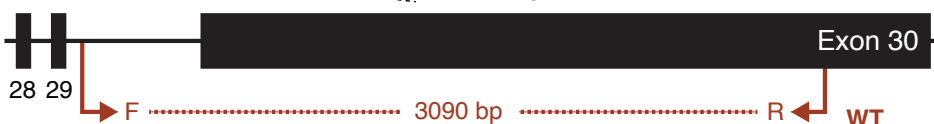

3090 bp

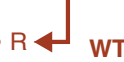

no Nhel - 3 Kb

HR donor Homology Arm 5'

Homology Arm 3

$\mathrm{KI}$

Nhel - $1.3 \& 1.7 \mathrm{~Kb}$

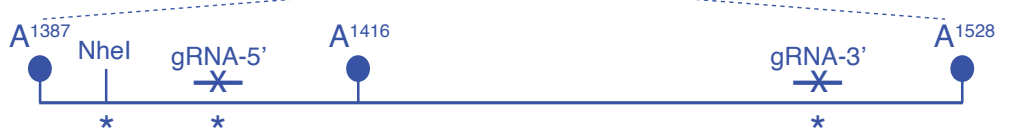

H
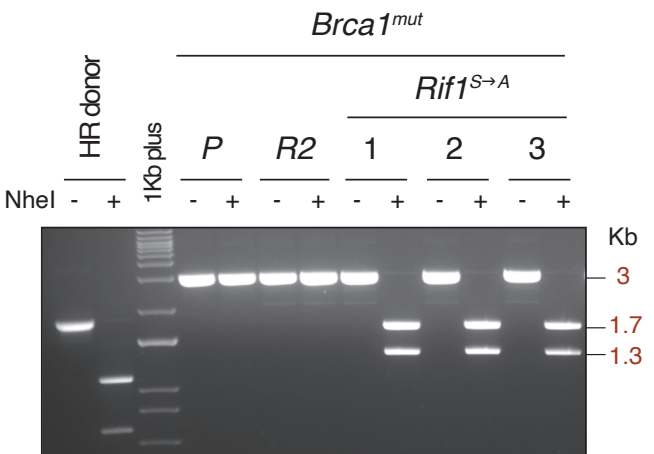
Figure S2. Generation of RIF1-mutant $\mathrm{CH} 12$ cell lines on a BRCA1deficient background. (A) Scheme of mouse Rif1 genomic locus (scheme adapted from Ensembl Rif1-201 ENSMUST00000112693.9) and location of gRNAs used in this study. The nickase gRNA pairs are gRif1-N1a and gRif1N1b for Nickase 1, and gRif1-N2a and gRif1-N2b for Nickase 2. (B) Genomic scar of two selected/representative Brca ${ }^{1{ }^{\text {ut }}}$ Rif1 ${ }^{-\%}$ clonal derivatives (Brca ${ }^{\text {mut }}$ Rif ${ }^{-}-1$ and Brca $1^{\text {mut }}$ Rif $1 \%$ - 2). The expected consequences at the protein level are indicated for each scar. The gRNAs employed to generate each cell line are highlighted in shades of blue with the PAM sequence in red. Ref: reference sequence; Indel: insertion and/or deletion; fs: amino acid frameshift; PTC: premature termination codon. (C) Western blot analysis of whole cell extracts from control Brca ${ }^{\text {mut }} R$ and $B r c a 1^{m u t} R i f 1^{-/}$cell lines. The arrowhead indicates RIF1 band whereas the asterisk symbol denotes aspecific bands that can be used as additional internal loading controls. (D) Graph depicting the average number of chromosomal aberrations in clonal derivatives of the indicated genotype following $1 \mu$ M PARPi treatment for $24 \mathrm{~h}(\mathrm{n}=50$ metaphases analyzed per genotype). Graph summarizes the results of two independent experiments performed on different control cell lines (Ctrl, either parental Brca ${ }^{\text {mut }}$ and/or $B r c a 1^{\text {mut }} R s$ ) and one Brca ${ }^{\text {mut }}$ Rif1\% clonal derivative. (E) Residual viability of control Brca ${ }^{\text {mut }} R$ s and Brca $1^{\text {mut }}$ Rif1 ${ }^{-1}$ cell lines after treatment with $1 \mu \mathrm{M}$ of PARPi for $72 \mathrm{~h}$. Graph summarizes three independent experiments per $\mathrm{Brca}^{\mathrm{mut}} \mathrm{Rif1}^{-1-}$ clone. (F) Dot plot depicting CSR to $\lg \mathrm{A}$ in activated control $\left(B r c a 1^{\text {mut }} R\right)$ and two selected Brca ${ }^{\text {mut }}$ Rif1 $1^{-1}$ cell lines. The graph summarizes three independent experiments per Brca 1 ${ }^{\text {mut }}$ Rif1 1 cell line with CSR efficiencies within each experiment normalized to either one, or the average CSR value of two, control Brca ${ }^{\text {mut }} R$, which was set to $100 \%$. (G) Schematic representation of the knock-in strategy employed for the Ser to Ala mutagenesis at the conserved SQ motifs in the IDR-Cll cluster. Location of primers ( $F$, forward; $R$, reverse) and expected PCR digestion products employed for initial assessment of targeting results are indicated in dark red. KI: knock-in. "*” indicates silent mutations introduced to create the Nhel diagnostic restriction site and to render the knocked-in sequences resistant to CRISPR-Cas9 digestion. $(\mathrm{H})$ Characterization of selected Brca $1^{\text {mut }}$ Rif $1^{S \rightarrow A}$ $\mathrm{CH} 12$ cell lines by diagnostic digestion. The bands refer to the Nhelundigested and -digested products of the PCR analysis performed with the primers indicated in panel $\mathrm{G}$. Note that the undigested and digested products of the donor DNA PCR fragment (digestion control) are of smaller size compared to the cell line sample fragments because they are amplified with primers inside the homology arms of the donor plasmid. The control cell line samples comprise the parental Brca $1^{\text {mut }} 1$ cell line $(\mathrm{P})$ and a $B r c a 1^{\text {mut }} R$ clonal derivative. Significance in panels $E$ and $F$ was calculated with the MannWhitney U test, and error bars represent SD. ${ }^{*}=p \leq 0.05$; ${ }^{* *}=p \leq 0.01$. 


\section{Phosphorylation of the IDR-CII SQ cluster is dispensable for RIF1 ability}

\section{to inhibit DSB end resection}

To investigate whether the phosphorylation status of the conserved IDR-CII $S Q$ cluster is required for RIF1 ability to inhibit DSB end resection, we abrogated phosphorylation of $S^{1387} Q, S^{1416} Q$, and $S^{1528} Q$ motifs by serine to alanine substitutions in Brca ${ }^{\text {mut }} \mathrm{CH} 12$ cells via CRISPR-Cas9-mediated knock-in mutagenesis at the Rif1 locus (Fig. $2 \mathrm{~F}$ and S2, G and H). This knockin approach allows the characterization of the PTM-dependent regulation of RIF1 biological functions under physiological levels of protein expression. Despite the expected HR-deficiency of Brca ${ }^{\text {mut }}$ cells, we obtained several clonal derivatives that harboured the desired mutations (Brca $\left.1^{m u t} R_{i f 1}{ }^{S \rightarrow A}\right)$, and expressed wild-type levels of RIF1 (Fig. 2F). To control for any clonalityrelated issue, we employed three independent clonal derivatives for all subsequent analyses.

We first asked whether preventing phosphorylation of the IDR-CII SQ cluster affected RIF1 ability to inhibit resection during repair of DNA replication DSBs. To do so, we assessed chromosomal aberrations and viability following PARPi treatment. All Brca $1^{m u t} R_{i f}{ }^{S \rightarrow A}$ cell lines accumulated chromatid breaks and radial chromosomes to the same levels as the control Brca ${ }^{m u t}$ genotype (Fig. 2G) and were as sensitive to the treatment (Fig. 2H). In contrast, Brca1 ${ }^{\text {mut }}$ Rif1 $1 \%$ cells exhibited the expected reduction in chromosomal aberrations and rescue of viability (Fig. 2, G and H). These results show that abrogation of phosphorylation events at the conserved cluster does not affect RIF1's role in promoting genome instability in BRCA1-deficient cells.

We next assessed the contribution of IDR-CII SQ cluster phosphorylation on CSR, which is dependent on RIF1 ability to protect CSR breaks against resection (Chapman et al., 2013; di Virgilio et al., 2013; Escribano-Díaz et al., 2013). To this end, we stimulated control and Brca $1^{\text {mut }}{ }^{\text {Rif }}{ }^{S \rightarrow A}$ cell lines with $\alpha \mathrm{CD} 40, \mathrm{TGF} \beta$ and IL-4, and monitored CSR efficiencies. Whereas Brca1 ${ }^{\text {mut }}$ Rif1 ${ }^{-1}$ cells were, as expected, severely impaired in the process, Brca $^{m u t}{ }^{m i f}{ }^{S \rightarrow A}$ cell lines all switched proficiently from expressing $\lg M$ to $\lg A$ 
(Fig. 2I). This finding indicates that phosphorylation of the conserved IDR-CII $\mathrm{SQ}$ motifs is dispensable for physiological levels of CSR.

We concluded that RIF1-mediated DSB end protection activity is not dependent on the phosphorylation of the conserved IDR-CII SQ cluster.

\section{Phosphorylation of the IDR-CII SQ cluster enables RIF1-dependent protection of stalled DNA replication forks}

RIF1 has recently been reported to play a genome-protective role under conditions of DNA replication stress (Chaudhuri et al., 2016; Garzón et al., 2019; Mukherjee et al., 2019). RIF1 is recruited to stalled DNA replication forks where it protects nascent DNA from degradation by the DNA2 nuclease in a manner dependent on its interaction with Protein Phosphatase 1 (PP1) (Chaudhuri et al., 2016; Garzón et al., 2019; Mukherjee et al., 2019). This activity allows for timely restart of stalled forks and prevents genome instability (Garzón et al., 2019; Mukherjee et al., 2019). Given the high proliferative nature of the cellular context where phosphorylation of the conserved IDR-CII SQ motifs was originally detected (activated primary B cells, Fig. 1), we asked whether these PTMs could influence RIF1 function during replication stress.

BRCA1 plays a protective role at DNA replication forks that is independent from RIF1 (Chaudhuri et al., 2016; Garzón et al., 2019; Mukherjee et al., 2019; Schlacher et al., 2012). Therefore, to specifically address the contribution of RIF1 phosphorylation to fork protection, we first generated a set of Rif1 knock-out and $\mathrm{A}^{1387} \mathrm{~A}^{1416} \mathrm{~A}^{1528}$-bearing phosphomutant cell lines on a BRCA1-proficient background (WT CH12 cells) (Rif1 ${ }^{-1}$ and Rif1 ${ }^{S \rightarrow A}$, Fig. 3A and S3, A to C). As expected, deletion of RIF1 severely impaired CSR ((Chapman et al., 2013; di Virgilio et al., 2013; Escribano-Díaz et al., 2013) and Fig. S3D), whereas, in agreement with the findings from the BRCA1deficient background (Fig. 2l), CSR was not affected in Rif $1^{S \rightarrow A}$ cell lines (Fig. S3D). 
Next, we applied the DNA fiber assay to monitor the degradation of nascent DNA at forks that were stalled via treatment with Hydroxyurea (HU) (Fig. 3B). $\mathrm{HU}$ interferes with DNA synthesis by inhibiting ribonucleotide reductase, the rate-limiting enzyme in dNTP synthesis (Singh and Xu, 2016). Both Rif1 $\%$ and Brca $1^{\text {mut }}$ genotypes exhibited the expected fork degradation phenotype (Fig. $3 \mathrm{C}$ ), thus indicating that the protective pathways mediated by these factors are active also in $\mathrm{CH} 12$ cells. Interestingly, Rif $^{S \rightarrow A}$ clonal derivatives showed increased degradation of stalled forks compared to controls, and to the same levels observed in Rif1\% cells (Fig. 3C), thus suggesting that abrogation of these IDR-CII SQ phosphorylation events prevents RIF1 function at the forks.

RIF1 protective role at stalled forks is dependent on the ability of its interactor PP1 to dephosphorylate and inactivate DNA2, which in turn limits the nuclease-mediated processing of DNA replication forks (Garzón et al., 2019; Mukherjee et al., 2019). To confirm the DNA2-dependency of the fork degradation phenotype observed in cells expressing phospho-mutant RIF1 protein, we repeated the DNA fiber assay in the presence of the DNA2 inhibitor NSC-105808 (DNA2i) (Garzón et al., 2019; Kumar et al., 2017). Analogously to the result observed in Rif1\% cells (Fig. 3D and (Garzón et al., 2019; Mukherjee et al., 2019)), DNA2i treatment rescued the fork degradation phenotype in all $\mathrm{HU}$-treated Rif ${ }^{S \rightarrow A}$ clonal derivatives (Fig. 3D).

We concluded that phosphorylation of the conserved IDR-CII SQ cluster enables RIF1-dependent inhibition of DNA2 activity and protection of nascent DNA at stalled replication forks. 


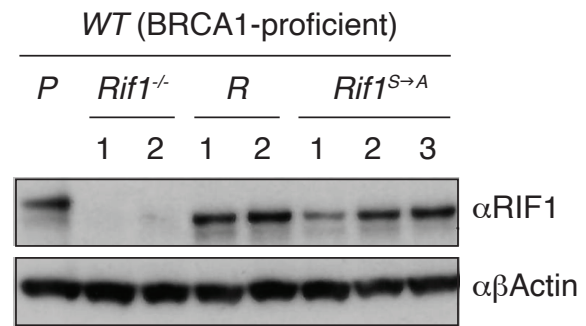

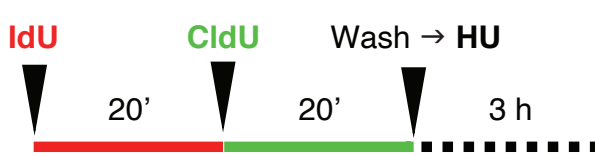

Replication direction

DNA degradation
CldU/ldU = 1

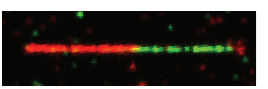

Protected fork

CldU/ldU $<1$

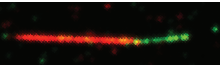

Degraded fork

C

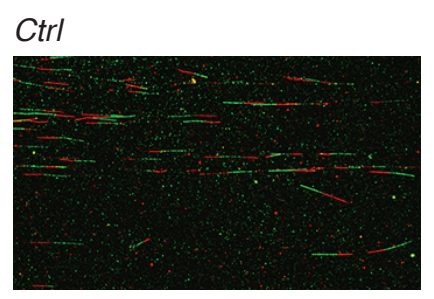

Rif1\%

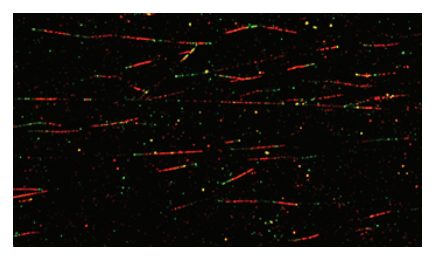

Brca1 $^{m u}$

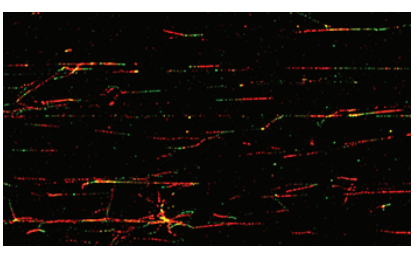

$\operatorname{Rif1}^{S \rightarrow A}$

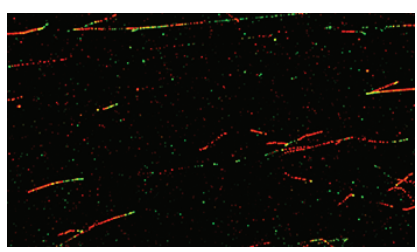

D
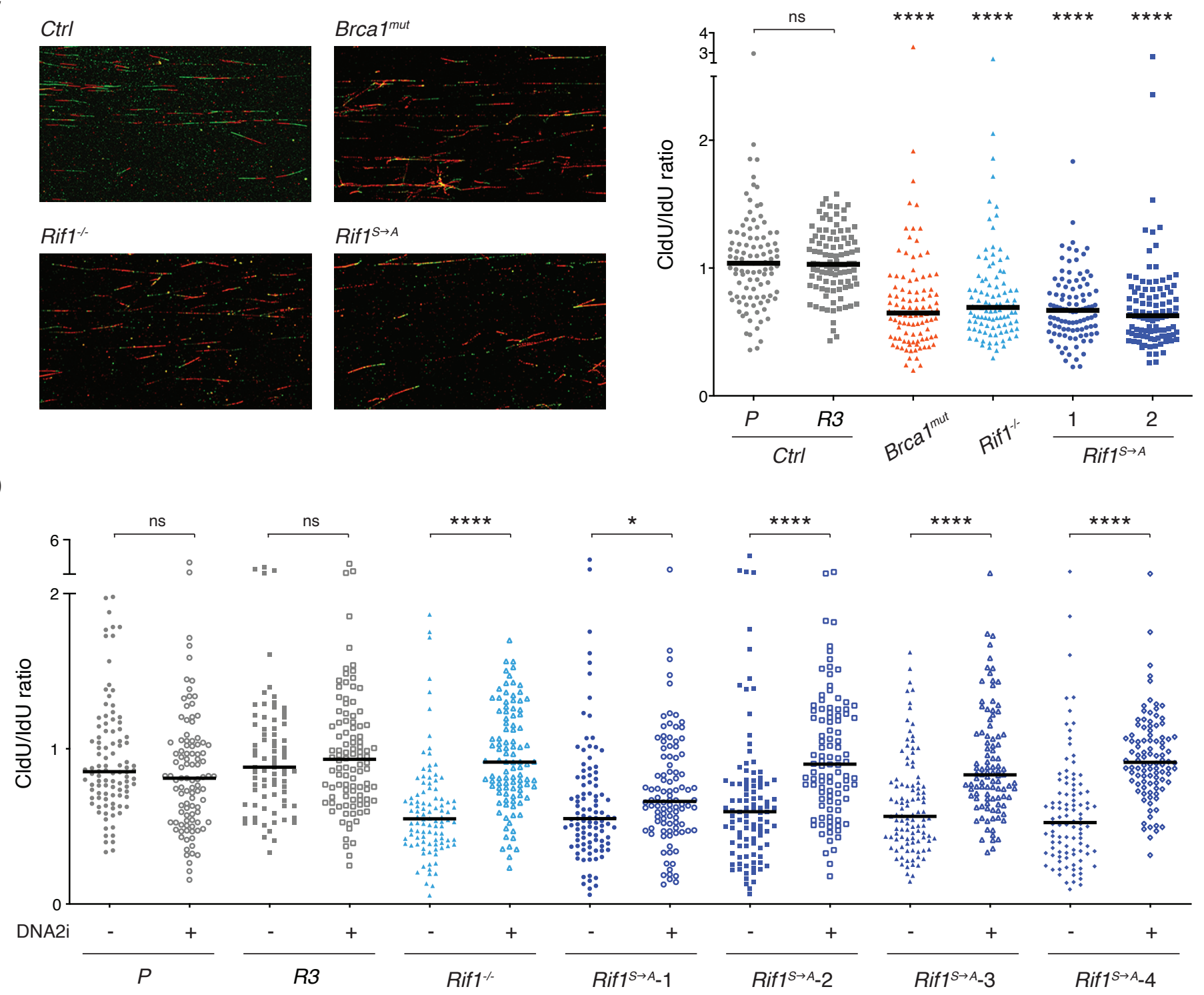
Figure 3. Phosphorylation of the conserved IDR-CII SQ cluster enables RIF1-dependent protection of nascent DNA at stalled replication forks.

(A) Western blot analysis of whole cell extracts from independent cells lines of the indicated genotypes (Rif1 ${ }^{-/}$, control Random clones $R$, and $R i f 1^{S \rightarrow A}$, all generated on the parental - $P$ - WT CH12 background). (B) Left: Schematic representation of the DNA fiber assay employed to assess protection of nascent DNA at stalled replication forks. Right: Representative images of protected and degraded DNA fibers. (C) Left: Representative fields for the analysis of nascent DNA degradation following $3 \mathrm{~h}$ treatment with $4 \mathrm{mM} \mathrm{HU}$ in $\mathrm{CH} 12$ cells of the indicated genotypes. Right: Graph summarizing the quantification of CldU/ldU ratio for $n=100$ DNA fibers analyzed per genotype ( 1 and 2 indicate two different $R$ iff ${ }^{S \rightarrow A}$ clonal derivatives). The graph is representative of three independently performed experiments. (D). Graph summarizing the quantification of CldU/ldU ratio for $n \geq 100$ DNA fibers analyzed per genotype in HU-treated cells in the absence/presence of $0.3 \mu \mathrm{M}$ DNA2i (four different $R i f 1^{S \rightarrow A}$ clonal derivatives were employed). The graph is representative of two independently performed experiments. Significance in panels $C$ and $D$ was calculated with the Mann-Whitney $U$ test, and the median is indicated. Significance for each cell line in the graph in panel $C$ was calculated in reference to the parental $\mathrm{CH} 12(P)$ sample. ns = not significant; * $=p \leq 0.05 ;{ }^{* * *}=p<0.0001$. 
A

Rif1 $^{-/}-1$

Ref

Scar 1

Scar 2

Rif1 $^{-/}-2$

Ref

Scar 1/2
gRif1-N1b

gRif1-N1a

GGCCCCAGGTCGCAGCCCCCTGGAGCCGCTTCTGGAGACTTGGGAAGACCCCTCGGTGCCTCCGGGAGAGCAGACGGACGCCTACCTAACTCT

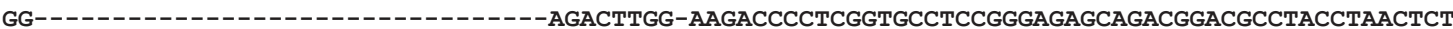
GGCCCCAGGTCGCAGCCCCCTGGAGCCGCTTCTGGAGA

gRif1-N2a

CTGCTTTTAACCTTGAATGGTATCATTAAGAGTTCAGACAAAAATGTGTGTACCAGGGCACTGTGGGTAATATCCAAACAGACGTTTCCTGCT СTGCTTTTAACCTTGAATGGTATCATTAAGAGTTCAGACAAAAA------_----_-----CTGTGGGTAATATCCAAACAGACGTTTCCTGCT
Indel result

I

fs \& PTC

fs \& PTC
B

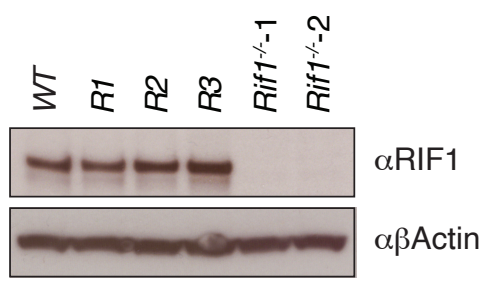

C

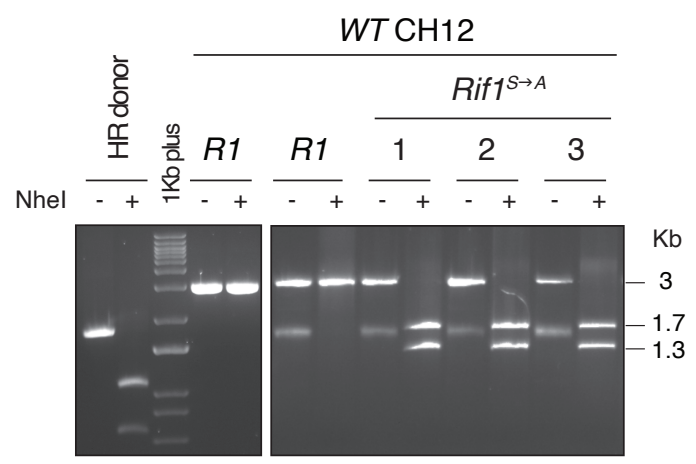

D
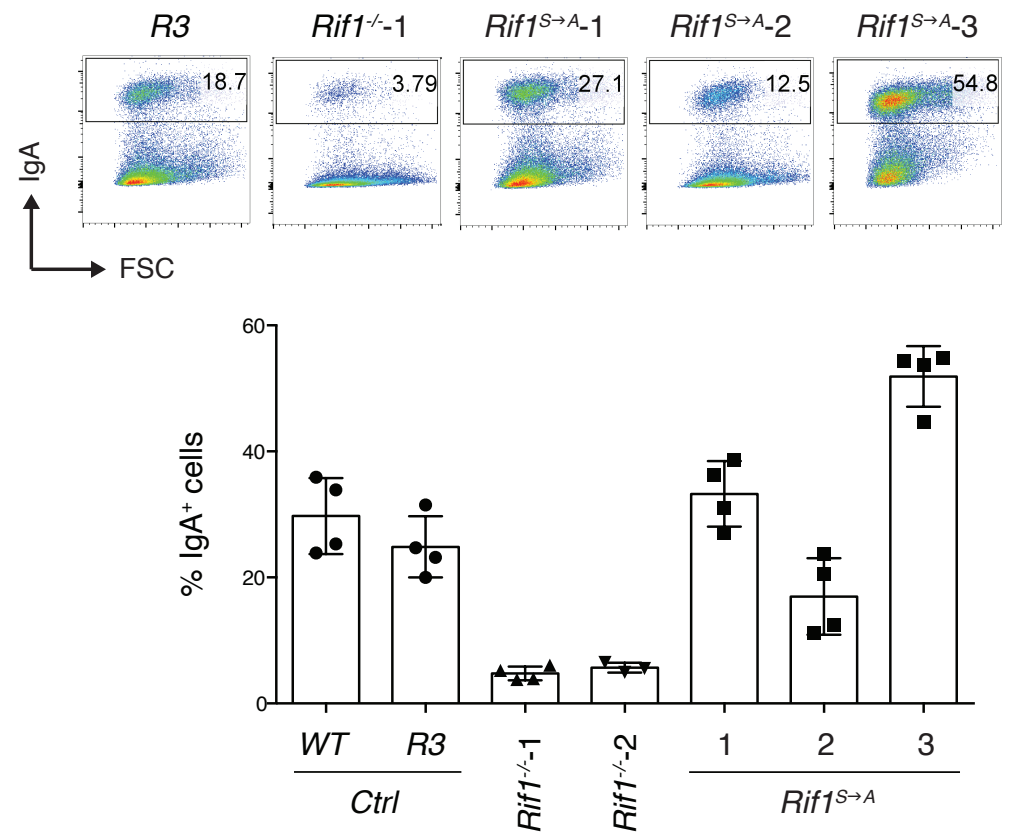
Figure S3. Generation of RIF1-mutant $\mathrm{CH1} 2$ cell lines on a WT background. (A) Genomic scar of two selected Rif1\% clonal derivatives (Rif1$1-1$ and $\left.R i f 1^{-1}-2\right)$. The expected consequences at the protein level are indicated for each scar. The gRNAs employed to generate each cell line are highlighted in shades of blue with the PAM sequence in red. Ref: reference sequence; Indel: insertion and/or deletion; fs: amino acid frameshift; PTC: premature termination codon. (B) Western blot analysis of whole cell extracts from controls and two different Rif1 knock-out cell lines (Rif $1 \%-1$ and Rif ${ }^{-1}-2$ ). Controls: WT parental $\mathrm{CH} 12$ cultures and clonal cell lines derived from targeting $\mathrm{CH} 12$ cells with gRNAs against random $(\mathrm{R})$ sequences not present in the mouse genome (validated Random clones on the WT background, R1, $R 2$, and $R 3$ ). (C) Characterization of selected Rif1 ${ }^{S \rightarrow A} \mathrm{CH} 12$ cell lines by diagnostic digestion, which followed the same scheme as for Brca $1^{\text {mut }}$ Rif $^{S \rightarrow A}$ clonal derivatives in Fig. S2, panels $G$ and $H$. (D) Top: Representative flow cytometry plots measuring CSR to $\lg A$ in activated cell lines of the indicated genotype (Rif1 ${ }^{S \rightarrow A}-1$, Rif $^{S \rightarrow A}-2$, and Rif $^{S \rightarrow A}-3$ are independent clonal derivatives). Bottom: Summary graphs for four independent experiments. 


\section{Discussion}

The regulation of DNA processing and its consequences for the preservation of genome integrity have important clinical implications. On the one hand, down-regulation or inactivating mutations in DSB end protection factors confer resistance to PARP inhibitors in BRCA1-deficient tumors in mice and a patient-derived model (Dev et al., 2018; Jaspers et al., 2013; Noordermeer et al., 2018; Xu et al., 2015). On the other hand, protection of DNA replication forks has recently been proposed as a mechanism for chemoresistance in the context of BRCA-deficiency (Chaudhuri et al., 2016). Hence, the dissection of pathways and molecular determinants in the regulation of DNA processing has profound implications for the development and improvement of targeted antitumoral treatments.

RIF1 plays at least two, and to some extent conflicting, roles in the preservation of genome integrity during DNA replication: a genome-protective role in stabilizing nascent DNA at stalled but unbroken forks, and a potentially genome-destabilizing role in regulating DNA repair by opposing resection at DSBs. Both roles depend on RIF1 ability to control DNA processing, albeit on different DNA substrates and via independent mechanisms: the protection of newly replicated DNA at stalled forks through PP1-induced DNA2 inactivation (Garzón et al., 2019; Mukherjee et al., 2019), and the inhibition of DSB resection at collapsed forks via the 53BP1-triggered cascade (Chapman et al., 2013; Escribano-Díaz et al., 2013; Feng et al., 2013; Zimmermann et al., 2013), respectively. Given the impact of these pathways on genome stability and cell viability, it is likely that multiple layers of regulations have evolved to ensure the coordination of RIF1 activities in the control of DNA processing. In this study, we identified three serine residues that are phosphorylated in hyper-proliferative $B$ lymphocytes. This set of phospho-sites is specifically required for the role of RIF1 at stalled forks, and as such, exerts a genome protective function under conditions of DNA replication stress.

Interestingly, the identified PTMs occur within a cluster of conserved SQ motifs in the IDR of mammalian RIF1. IDRs are stretches of sequences that 
do not adopt any stable, defined secondary or tertiary structures (Wright and Dyson, 2015). Proteins characterized by a high degree of intrinsic disorder rapidly transition between different folding states. Phosphorylation of key residues within IDRs has been shown to influence protein folding, interaction with binding partners, and as a consequence, protein function in several biological settings (Bah and Forman-Kay, 2016; Wright and Dyson, 2015). As a relevant example, phosphorylation of 53BP1 SQ/TQ motifs within its intrinsically disordered $\mathrm{N}$-terminus is essential for the DNA damagedependent recruitment of RIF1 to sites of damage and protection against DSB resection (Chapman et al., 2013; di Virgilio et al., 2013; Escribano-Díaz et al., 2013; Feng et al., 2013; Silverman et al., 2004; Zimmermann et al., 2013).

Orthologous IDRs exhibit molecular features that are crucial for function but do not translate into any noticeable similarity at the level of primary amino acid sequences (Zarin et al., 2019, 2017). These molecular features, which include for instance length, complexity and net charge, appear to be under evolutionary selection, thus explaining how the functional output of IDRs could be maintained despite highly divergent amino acid sequences (Zarin et al., $2019,2017)$. The phosphorylation of a set of IDR SQ motifs that we report in this study for mammalian RIF1 could represent such an evolutionary signature. In this regard, the IDR of $S$. cerevisiae Rif1 contains a cluster of seven SQ/TQ consensus motifs for the ATM/ATR yeast homologs Tel1/Mec1, some of which have been reported to be phosphorylated in vivo (Smolka et al., 2007; Sridhar et al., 2014; Wang et al., 2018). Interestingly, a recent bioRxiv manuscript showed that abrogation of phosphorylation at these seven SQ/TQ sites in yeast Rif1 impaired DNA replication fork protection after treatment with HU (Monerawela et al., 2020). Although RIF1 IDRs exhibit low conservation across evolution, the identification of a cluster of SQ/TQ motifs whose phosphorylation influences fork protection in both mammalian and yeast RIF1 hints at an evolutionary conserved mechanism, and underlying molecular feature, for the regulation of nascent DNA processing under conditions of DNA replication stress. 


\section{Materials \& Methods}

\section{Mice and derived primary cell cultures}

Rif1 ${ }^{F H F H}$ (Cornacchia et al., 2012) and Rif1 F/FCd19Cre/+ (di Virgilio et al., 2013) mice were previously described and maintained on a C57BL/6 background. Mice were kept in a specific pathogen-free (SPF) barrier facility under standardized conditions $\left(20+/-2{ }^{\circ} \mathrm{C}\right.$ temperature; $55 \% \pm 15 \%$ humidity) on a 12 $\mathrm{h}$ light/12 $\mathrm{h}$ dark cycle. Mice of both genders were used for the experiments. All experiments were performed in compliance with the European Union (EU) directive 2010/63/EU, and in agreement with Landesamt für Gesundheit und Soziales directives (LAGeSo, Berlin, Germany).

Primary cell cultures of resting $B$ lymphocytes were isolated from $W T$, Rif1 ${ }^{\mathrm{FH} / F H}$ and Rif1 ${ }^{\mathrm{F} / F} \mathrm{Cd} 19^{\mathrm{Cre} /+}$ mouse spleens using anti-CD43 MicroBeads (Miltenyi Biotec), and grown in RPMI 1640 medium (Life Technologies) supplemented with 10\% fetal bovine serum (FBS), 10 mM HEPES (Life Technologies), 1 mM Sodium Pyruvate (Life Technologies), 1X Antibiotic Antimycotic (Life Technologies), $2 \mathrm{mM}$ L-Glutamine (Life Technologies), and

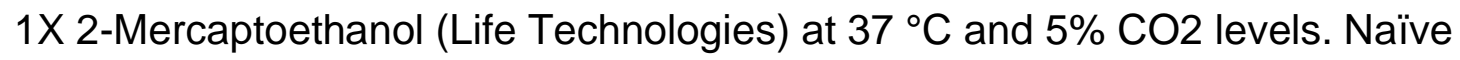
B cells were activated by addition of $25 \mu \mathrm{g} / \mathrm{ml}$ LPS (Sigma-Aldrich), $5 \mathrm{ng} / \mathrm{ml}$ of mouse recombinant IL-4 (Sigma-Aldrich), and $0.5 \mu \mathrm{g} / \mathrm{ml}$ anti-CD180 (RP/14) (BD Biosciences) to the cultures upon isolation.

Primary MEFs (pMEFs) were isolated from $W T$ and Rif1 ${ }^{F H / F H}$ mice as it follows. Pregnant mice were sacrificed on day E12.5 by cervical dislocation, and embryos were removed from uterine horns and placed individually in plates containing PBS (Thermo Fisher Scientific). Brain, tail, limbs and dark red organs were removed and the remaining tissue was transferred into fresh PBS. Tissue was treated with $2 \mathrm{ml}$ of Trypsin-EDTA $0.05 \%$ (Gibco) at $37^{\circ} \mathrm{C}$ for $15 \mathrm{~min}$, and cell suspension was passed through a syringe with gauge 18 needle. Trypsin was neutralized with DMEM medium (Life Technologies) supplemented with 10\% FBS, 2 mM L-Glutamine, and Penicillin-Streptomycin (Life Technologies). pMEFs from each embryo were expanded in $25 \mathrm{~cm}$ plates at $37^{\circ} \mathrm{C}$ and $5 \% \mathrm{CO} 2$ levels to reach $80 \%$ confluency, and either used immediately for immortalization (see below) or frozen. 


\section{Cell lines}

653

The cell lines employed for this study are: $\mathrm{CH} 12(\mathrm{CH} 12 \mathrm{~F} 3$, mouse, (Nakamura et al., 1996); Rif1 ${ }^{-1} \mathrm{CH} 12$ (clone 1, mouse, (Delgado-Benito et al., 2018)); WT (Random clones), Rif1\% (clone 2), and Brca $1^{\text {mut }} \mathrm{CH} 12$ clonal derivatives (mouse, this paper), as well as RIF1 phosphomutant $\mathrm{CH} 12$ cell lines generated on both WT and Brca ${ }^{\text {mut }}$ backgrounds (mouse, this paper); WT and Rif1 ${ }^{F H / F H}$ immortalized mouse embryonic fibroblasts (iMEFs, this paper). iMEFs were generated by immortalization of the pMEFs cultures described above via retroviral transduction of a construct expressing the SV40 T-antigen.

CH12 cells were grown in RPMI 1640 medium supplemented with 10\% FBS, $10 \mathrm{mM}$ HEPES, $1 \mathrm{mM}$ Sodium Pyruvate, 1X Antibiotic Antimycotic, $2 \mathrm{mM} \mathrm{L-}$ Glutamine, and $1 \times 2-$ Mercaptoethanol at $37{ }^{\circ} \mathrm{C}$ and $5 \% \mathrm{CO} 2$ levels. iMEFs were cultured in DMEM medium supplemented with 10\% FBS, 2 mM LGlutamine, and Penicillin-Streptomycin at $37^{\circ} \mathrm{C}$ and $5 \% \mathrm{CO} 2$ levels.

\section{Identification of RIF1 phosphoresidues}

RIF1 phosphoresidues were identified via analysis of RIF1 I-DIRT samples prepared from primary B cell cultures as previously described (DelgadoBenito et al., 2018), with the only difference that preparations with varying concentrations of Glutaraldehyde ( 1 - $5 \mathrm{mM}$ ) were employed. Samples were loaded on NuPAGE Bis-Tris Gels (ThermoFisher Scientific) and run for a short time to produce gel plugs. The gel samples were subjected to in-gel tryptic digestions. Peptides were extracted, purified, and analyzed by LC-MS using a Thermo Orbitrap Fusion mass spectrometer, with a Thermo Easy-nLC 1000 HPLC and a Thermo Easy-Spray electrospray source. Isotopically labelled proteins were identified by searching against a mouse protein sequence database using the GPM software (Beavis, 2006), which was set to search for tryptic peptides whose lysines and arginines were isotopically labelled and for potential phosphorylation modifications at serines, threonines and tyrosines.

\section{CSR assay}


$\mathrm{CH} 12$ cells were stimulated to undergo CSR to IgA by treatment with 1-5 $\mu \mathrm{g} / \mathrm{mL} \alpha \mathrm{CD} 40$ (BioLegend), $5 \mathrm{ng} / \mathrm{ml} \mathrm{TGF} \beta$ (R\&D Systems) and $5 \mathrm{ng} / \mathrm{ml}$ of mouse recombinant IL-4 for $48 \mathrm{~h}$. For class switching analysis, cell suspensions were stained with fluorochrome-conjugated anti-IgA (Southern Biotech) and samples were acquired on an LSRFortessa cell analyzer (BDBiosciences).

\section{CRISPR-Cas9 gene targeting \& generation of $\mathrm{CH} 12$ clonal cell lines}

Targeting of Brca1 and Rif1 loci for generation of indel-bearing clonal derivatives was performed with $2 \mathrm{gRNA}$ pairs per gene ( $\mathrm{g}$ Gene-N1a and g Gene-N1b for Nickase 1, and g Gene-N2a and g Gene-N2b for Nickase 2) cloned into tandem U6 cassettes in a version of pX330 plasmid (pX330-U6Chimeric_BB-CBh-hSpCas9, Addgene \#42230) mutated to express Cas9D10A T2A-GFP (Nickase-1/2). The Nickase-1/2 constructs were individually transfected into $\mathrm{CH} 12$ via electroporation with Neon Transfection System (Thermo Fisher Scientific).

For the generation of Rif $1^{S \rightarrow A}$ and $B r c a 1^{m u t}$ Rif $1^{S \rightarrow A}$ cell lines, gRNAs targeting Rif1 exon 30 (gRNA-5' and gRNA-3') were cloned into tandem U6 cassettes in a variant of the original pX330 plasmid (pX330-U6-Chimeric_BB-CBhhSpCas9, Addgene \#42230) modified to express Cas9 ${ }^{W T}$-T2A-GFP (pX330Cas9 ${ }^{W T}$-T2A-GFP, kind gift from Van Trung Chu, MDC). $\mathrm{CH} 12$ cells (parental WT and Brca1 ${ }^{\text {mut }}$-1) were co-electroporated with the gRNA-5'/3'-expressing construct and a circular donor plasmid carrying the synthesized knock-in template (GeneArt ${ }^{\circledR}$ Invitrogen ${ }^{\mathrm{TM}}$ ).

For the generation of both indel- and knock-in-bearing clonal derivatives, single GFP-positive cells were sorted in 96-well plates $40 \mathrm{~h}$ after electroporation, and allowed to grow for ca. 12 days before expansion of selected clones. Clonal cell lines were validated at the level of genomic scar (all clonal derivatives), protein level (RIF1 in Brca $1^{\text {mut }}$ Rif1 $^{-1}, B r c a 1^{\text {mut }}$ Rif ${ }^{S \rightarrow A}$, Rif1 $^{-/}$, and Rif1 ${ }^{S \rightarrow A}$ ), and phenotypic consequences (BRCA1-deficiency-driven genome instability and lethality in Brca $1^{\text {mut}}$ ). Random control cell lines were generated with gRNAs against random sequences not present in the mouse genome (random gRNAs pairs-Cas9 ${ }^{\mathrm{D} 10 \mathrm{~A}}$ constructs). 
For in bulk targeting of Brca $1^{\text {mut }} 1$ cells in the rescue-of-viability assay, gRNAs against random sequences, 53bp1, Rif1, and Rev7 genes were cloned into the $\mathrm{U} 6$ cassette of $\mathrm{pX} 330$-Cas ${ }^{\mathrm{WT}}$-T2A-GFP. Brca $1^{\text {mut }} 1$ cells were transfected with the Cas9-gRNAs expressing constructs via electroporation, sorted for GFP-positive cells after $40 \mathrm{~h}$, left to recover for $72 \mathrm{~h}$, and then treated with 1 $\mu \mathrm{M}$ PARPi for $72 \mathrm{~h}$ before assessment of cell viability.

The sequences of the gRNAs and genotyping primers employed in this study are listed in Table S3.

\section{Western blot analysis}

Western blot analysis of protein levels was performed on whole cell lysates prepared by lysis in RIPA buffer (Sigma) supplemented with $1 \mathrm{mM}$ DTT (Sigma), Complete EDTA free proteinase inhibitors (Roche) and Pierce Phosphatase Inhibitor Mini Tablets (ThermoFisher). The antibodies used for WB analysis are: anti-FLAG M2 (Sigma), anti-RIF1 (di Virgilio et al., 2013), anti-Tubulin (Abcam) and anti- $\beta$ Actin (Sigma).

\section{Cell viability \& Metaphase analysis}

For assessment of cell viability, $\mathrm{CH} 12$ cells were either mock-treated (DMSO, Carl Roth) or incubated with $1 \mu \mathrm{M}$ PARPi (Olaparib - AZD2281, Selleckchem) for $72 \mathrm{~h}$. Residual viability was expressed as percentage of cell viability of PARPi- over DMSO-treated cultures.

For genomic instability analysis, exponentially growing cells were treated with DMSO or $1 \mu \mathrm{M}$ PARPi for $24 \mathrm{~h}$ followed by 45 min incubation at $37^{\circ} \mathrm{C}$ with Colcemid (Roche). Metaphase preparation and aberration analysis were performed as it follows. Cell pellets were resuspended in $0.075 \mathrm{M} \mathrm{KCl}$ at $37^{\circ} \mathrm{C}$ for $15 \mathrm{~min}$ to perform a hypotonic shock, and washed/fixed with 3:1 methanol (VWR)/glacial-acetic acid (Carl Roth) solution for $30 \mathrm{~min}$ at RT. Metaphase spreads were prepared by dropping fixed cells on microscope slides, which were air-dried and placed at $42^{\circ} \mathrm{C}$ for $1 \mathrm{~h}$. Giemsa staining was performed by using KaryoMAX Giemsa Stain Solution and 1X Gurr Buffer (tablets, Gibco). Metaphases were acquired with the Automated Metaphase Finder System Metafer4 (MetaSystems). 


\section{DNA fiber assay}

Degradation of nascent DNA at stalled forks was assessed as it follows.

Exponentially growing $\mathrm{CH} 12$ cells were sequentially pulse-labelled with $40 \mu \mathrm{M}$ of Idoxuridin (IdU) (Sigma-Aldrich) and $400 \mu \mathrm{M}$ of 5-Chloro-2'-deoxyuridine thymidine (CldU) (Sigma-Aldrich) for exactly 20 min each, washed once with 1X PBS, and treated with $4 \mathrm{mM} \mathrm{HU}$ for $3 \mathrm{~h}$. Cells were collected and resuspended in 1 X PBS at a concentration of $3.5 \times 10^{5}$ cells $/ \mathrm{ml}$. $3 \mu$ of cell suspension was diluted with $10 \mu$ of lysis buffer (200 mM Tris- $\mathrm{HCl}$ pH 7.5, 50 $\mathrm{mM}$ EDTA, and $0.5 \%(\mathrm{w} / \mathrm{v}) \mathrm{SDS}$ ) on a glass slide and incubated for $2 \mathrm{~min}$ at RT. The slides were titled at $15^{\circ}-60^{\circ}$, air dried and fixed with $3: 1$ methanol/acetic acid for $10 \mathrm{~min}$. Slides were denatured with $2.5 \mathrm{M} \mathrm{HCl}$ for 80 min, washed with 1X PBS and blocked with 5\% BSA (Carl Roth) in PBS for 40 min. The newly replicated CldU and IdU tracks were labelled for $1.5 \mathrm{~h}$ with anti-BrdU antibodies recognizing CldU (1:500, Abcam) and IdU (1:50, BD Biosciences), followed by 45 min incubation with secondary antibodies antimouse Alexa Fluor 488 (1:500, Invitrogen) and anti-rat Alexa Fluor 546 (1:500, Invitrogen). The incubations were performed in the dark in a humidified chamber. DNA fibers were visualized using a Carl Zeiss LSM800 confocal microscope at a 40X objective magnification, and images were analysed using ImageJ software. Whenever indicated, the DNA2 inhibitor NSC-105808 (Kumar et al., 2017) was added at a final concentration of $0.3 \mu \mathrm{M}$ for $24 \mathrm{~h}$ prior to $\mathrm{HU}$ addition.

\section{Protein sequence analysis}

The sequence alignment of RIF1 orthologs was performed simultaneously on the full-length proteins from all 18 species listed in Table S1 using the multiple sequence alignment program Clustal Omega (clustalo version 1.2.4, https://www.ebi.ac.uk/Tools/msa/clustalo/).

The disorder profile plots were determined by the Protein 모음der prediction System (PrDOS) server (https://prdos.hgc.jp/cgi-bin/top.cgi) (Ishida and

Kinoshita, 2007) using the template-based prediction option and with the prediction false positive rate set to $5.0 \%$. 
bioRxiv preprint doi: https://doi.org/10.1101/2021.11.04.467328; this version posted November 6, 2021. The copyright holder for this

preprint (which was not certified by peer review) is the author/funder, who has granted bioRxiv a license to display the preprint in perpetuity. It is made available under aCC-BY 4.0 International license.

784

785 Statistical analysis

786 The statistical significance of differences between groups/datasets was

787 determined by the Mann-Whitney $U$ test for all data presented in this study.

788 Statistical details of experiments can be found in the figure legends. 
Table S3. List of oligonucleotides used in this study.

\begin{tabular}{|c|c|c|c|}
\hline \multirow{13}{*}{$\begin{array}{l}\text { CRISPR-Cas9 } \\
\text { gene targeting } \\
\text { for clonal } \\
\text { derivative } \\
\text { generation }\end{array}$} & gRNAs & Sequence $\left(5^{\prime} \rightarrow 3^{\prime}\right)$ & Reference \\
\hline & gRandom-1a & GCGAGGTATTCGGCTCCGCG & Delgado-Benito et al., 2018 \\
\hline & gRandom-1b & ATGTTGCAGTTCGGCTCGAT & Delgado-Benito et al., 2018 \\
\hline & gBrca1-N1a & GAGCTACCACCGATGTTCCT & This paper \\
\hline & gBrca1-N1b & TCTCAGGGCACAGACTTTGC & This paper \\
\hline & gBrca1-N2a & GCGTTCAGAAAGTTAATGAG & This paper \\
\hline & gBrca1-N2b & TGTTATCCAAGGAACATCGG & This paper \\
\hline & gRif1-N1a & GAAGACCCCTCGGTGCCTCC & Delgado-Benito et al., 2018 \\
\hline & gRif1-N1b & AAGTCTCCAGAAGCGGCTCC & Delgado-Benito et al., 2018 \\
\hline & gRif1-N2a & TGTGTGTACCAGGGCACTGT & This paper \\
\hline & gRif1-N2b & ACTCTTAATGATACCATTCA & This paper \\
\hline & gRNA-5' & AAACACTCCGACGGTCTTCG & This paper \\
\hline & gRNA-3' & CGACTTGTCTAGATTGTCCA & This paper \\
\hline \multirow{11}{*}{$\begin{array}{l}\text { CRISPR-Cas9 } \\
\text { gene targeting } \\
\text { in in-bulk } \\
\text { cultures }\end{array}$} & gRNAs & & \\
\hline & gRandom-1a (as above) & GCGAGGTATTCGGCTCCGCG & Delgado-Benito et al., 2018 \\
\hline & $\mathrm{gRandom}-1 \mathrm{~b}$ (as above) & ATGTTGCAGTTCGGCTCGAT & Delgado-Benito et al., 2018 \\
\hline & gRandom-1c & GCTTTCACGGAGGTTCGACG & This paper \\
\hline & g53bp1-1 & CAGATGTTTATTATGTGGAT & Delgado-Benito et al., 2018 \\
\hline & g53bp1-2 & GAGTGTACGGACTTCTCGAA & Delgado-Benito et al., 2018 \\
\hline & gRif1- N2a (as above) & TGTGTGTACCAGGGCACTGT & This paper \\
\hline & gRif1- N2b (as above) & ACTCTTAATGATACCATTCA & This paper \\
\hline & gRev7-1 & CCTGATTCTCTATGTGCGCG & This paper \\
\hline & gRev7-2 & GTGCGCGAGGTCTACCCGGT & This paper \\
\hline & gRev7-3 & CTATGTGCGCGAGGTCTACC & This paper \\
\hline \multirow{16}{*}{$\begin{array}{l}\text { Analysis of } \\
\text { genomic scars }\end{array}$} & \multicolumn{3}{|l|}{ PCR primers } \\
\hline & \multicolumn{3}{|c|}{ Brca1 - Nickase 1 and 2 clones } \\
\hline & Fw & AAATGTGTGTGTGGAGCCATG & This paper \\
\hline & $\operatorname{Rev}$ & СTTCTCCAAACCAGTAGAGG & This paper \\
\hline & \multicolumn{3}{|l|}{ Rif1 - Nickase 1 clones } \\
\hline & Fw & GAGTAAATAAGCGCGAGCCG & Delgado-Benito et al., 2018 \\
\hline & $\operatorname{Rev}$ & CGATCCGGAGTTAGTGGGTT & Delgado-Benito et al., 2018 \\
\hline & \multicolumn{3}{|l|}{ Rif1 - Nickase 2 clones } \\
\hline & Fw & TTCCTTCCCTCAGTAGAG & This paper \\
\hline & Rev & GCAACAGGGCTGGCATTT & This paper \\
\hline & \multicolumn{3}{|l|}{ Rif1 $^{S \rightarrow A}-$ Rif1 locus } \\
\hline & Fw & GCGGTGCTTGAACTTCAGGG & This paper \\
\hline & Rev & GCTGCGTGCTCAGTCTCAAC & This paper \\
\hline & \multicolumn{3}{|l|}{ Rif1 $^{S \rightarrow A}-\mathrm{HR}$ donor } \\
\hline & Fw & TGTGGTGGCTCTGTTGCTGA & This paper \\
\hline & Rev & GCATGGTCACGAGCTTCACG & This paper \\
\hline
\end{tabular}




\section{Author contributions}

790 M.D.V., S.B., and M.A. conceived the main project idea and designed the

791 experiments; S.B. and M.A. contributed the majority of experiments; J.G.A.,

792 T.S., J.G., A.R., and D.B.R. performed experiments; M.D.V., S.B., and M.A.

793 analyzed and interpreted the data; W.Z. analysed the I-DIRT proteomic

794 datasets and identified RIF1 phosphoresidues; J.G. and A.D.D. contributed

795 their expertise and discussion on the fork protection phenotype; M.D.V.,

796 B.T.C., and A.D.D. supervised the experiments and/or analyses performed in

797 their respective groups; M.D.V. wrote the manuscript; M.D.V. and S.B. edited the manuscript; M.D.V. obtained the main funding for the project. 


\section{Acknowledgments}

800

801

We thank all members of the Di Virgilio lab for their feedback and discussion; V. Delgado-Benito and D. Sundaravinayagam (Di Virgilio lab, MDC, Berlin) for

803 their contributions to the project development; L. Keller (Di Virgilio lab, MDC, Berlin) for support with cloning, mutagenesis and mice genotyping; C. Brischetto (Scheidereit Lab, MDC, Berlin) for assistance with confocal microscopy; S. Hiraga (University of Aberdeen) for help with data analysis;

807 and the MDC FACS Core Facility and Dr. HP. Rahn for support with cell sorting. This work was supported by ERC grant 638897 (to M.D.V.), the Helmholtz-Gemeinschaft Zukunftsthema "Immunology and Inflammation" ZT0027 (to M.D.V.), and Cancer Research UK awards C1445/A19059 and DRCPGMI00013 (to A.D.D.). 


\section{References}

Bah A, Forman-Kay JD. 2016. Modulation of intrinsically disordered protein function by post-translational modifications. Journal of Biological Chemistry 291 :6696-6705. doi:10.1074/jbc.R115.695056

Beavis RC. 2006. Using the Global Proteome Machine for Protein IdentificationMethods in Molecular Biology. Totowa, NJ: Humana Press Inc. pp. 217-228.

Björkman A, Qvist P, Du L, Bartish M, Zaravinos A, Georgiou K, Børglum AD, Gatti RA, Törngren T, Pan-Hammarström Q. 2015. Aberrant recombination and repair during immunoglobulin class switching in BRCA1-deficient human B cells. Proceedings of the National Academy of Sciences of the United States of America 112:2157-2162. doi:10.1073/pnas.1418947112

Blackford AN, Jackson SP. 2017. ATM, ATR, and DNA-PK: The Trinity at the Heart of the DNA Damage Response. Molecular Cell. doi:10.1016/j.molcel.2017.05.015

Boboila C, Alt FW, Schwer B. 2012. Classical and Alternative End-Joining Pathways for Repair of Lymphocyte-Specific and General DNA DoubleStrand BreaksAdvances in Immunology. pp. 1-49. doi:10.1016/B978-012-394300-2.00001-6

Boersma V, Moatti N, Segura-bayona S, Peuscher MH, van der Torre J, Wevers BA, Orthwein A, Durocher D, Jacobs JJL. 2015. MAD2L2 controls DNA repair at telomeres and DNA breaks by inhibiting 5' end resection. Nature 521:537-540. doi:10.1038/nature14216

Bouwman P, Aly A, Escandell JM, Pieterse M, Bartkova J, van der Gulden H, Hiddingh S, Thanasoula M, Kulkarni A, Yang Q, Haffty BG, Tommiska J, Blomqvist C, Drapkin R, Adams DJ, Nevanlinna H, Bartek J, Tarsounas M, Ganesan S, Jonkers J. 2010. 53BP1 loss rescues BRCA1 deficiency and is associated with triple-negative and BRCA-mutated breast cancers. Nature Structural and Molecular Biology 17:688-695. doi:10.1038/nsmb.1831

Bunting SF, Callén E, Wong N, Chen HT, Polato F, Gunn A, Bothmer A, Feldhahn N, Fernandez-Capetillo O, Cao L, Xu X, Deng CX, Finkel T, Nussenzweig M, Stark JM, Nussenzweig A. 2010. 53BP1 inhibits homologous recombination in brca1-deficient cells by blocking resection of DNA breaks. Cell 141:243-254. doi:10.1016/j.cell.2010.03.012

Callen E, Di Virgilio M, Kruhlak MJ, Nieto-Soler M, Wong N, Chen HT, Faryabi RB, Polato F, Santos M, Starnes LM, Wesemann DR, Lee JE, Tubbs A, Sleckman BP, Daniel JA, Ge K, Alt FW, Fernandez-Capetillo O, Nussenzweig MC, Nussenzweig A. 2013. 53BP1 mediates productive and mutagenic DNA repair through distinct phosphoprotein interactions. Cell 153:1266-1280.

Cao L, Xu X, Bunting SF, Liu J, Wang RH, Cao LL, Wu JJ, Peng TN, Chen J, Nussenzweig A, Deng CX, Finkel T. 2009. A Selective Requirement for 53BP1 in the Biological Response to Genomic Instability Induced by Brca1 Deficiency. Molecular Cell 35:534-541. doi:10.1016/j.molcel.2009.06.037 DNA end joining and alternative pathways to double-strand break repair. 
Nature Reviews Molecular Cell Biology 18:495-506. doi:10.1038/nrm.2017.48

Chapman JR, Barral P, Vannier JB, Borel V, Steger M, Tomas-Loba A, Sartori AA, Adams IR, Batista FD, Boulton SJ. 2013. RIF1 Is Essential for 53BP1-Dependent Nonhomologous End Joining and Suppression of DNA Double-Strand Break Resection. Molecular Cell 49:858-871. doi:10.1016/j.molcel.2013.01.002

Chapman JR, Taylor MRG, Boulton SJ. 2012. Playing the End Game: DNA Double-Strand Break Repair Pathway Choice. Molecular Cell 47:497510. doi:10.1016/j.molcel.2012.07.029

Chaudhuri AR, Callen E, Ding X, Gogola E, Duarte AA, Lee JE, Wong N, Lafarga V, Calvo JA, Panzarino NJ, John S, Day A, Vidal Crespo A, Shen B, Starnes LM, de Ruiter JR, Daniel JA, Konstantinopoulos PA, Cortez D, Cantor SB, Fernandez-Capetillo O, Ge K, Jonkers J, Rottenberg S, Sharan SK, Nussenzweig A. 2016. Replication fork stability confers chemoresistance in BRCA-deficient cells. Nature 535:382-387. doi:10.1038/nature18325

Cornacchia D, Dileep V, Quivy JP, Foti R, Tili F, Santarella-Mellwig R, Antony C, Almouzni G, Gilbert DM, Buonomo SBC. 2012. Mouse Rif1 is a key regulator of the replication-timing programme in mammalian cells. $E M B O$ Journal 31:3678-3690. doi:10.1038/emboj.2012.214

Cortez D. 2015. Preventing replication fork collapse to maintain genome integrity. DNA Repair 32:149-157. doi:10.1016/j.dnarep.2015.04.026

Delgado-Benito V, Berruezo-Llacuna M, Altwasser R, Winkler W, Sundaravinayagam D, Balasubramanian S, Caganova M, Graf R, Rahjouei A, Henke M-T, Driesner M, Keller L, Prigione A, Janz M, Akalin A, di Virgilio M. 2020. PDGFA-associated protein 1 protects mature $B$ lymphocytes from stress-induced cell death and promotes antibody gene diversification. The Journal of Experimental Medicine 217:1-21. doi:10.1101/2020.01.30.917062

Delgado-Benito V, Rosen DB, Wang Q, Gazumyan A, Pai JA, Oliveira TY, Sundaravinayagam D, Zhang W, Andreani M, Keller L, Kieffer-Kwon KR, Pękowska A, Jung S, Driesner M, Subbotin RI, Casellas R, Chait BT, Nussenzweig MC, di Virgilio M. 2018. The Chromatin Reader ZMYND8 Regulates Igh Enhancers to Promote Immunoglobulin Class Switch Recombination. Molecular Cell 72:636-649. doi:10.1016/j.molcel.2018.08.042

Dev H, Chiang TW, Lescale C, de Krijger I, Martin AG, Pilger D, Coates J, Sczaniecka-clift M, Wei W, Ostermaier M, Herzog M, Lam J, Shea A, Demir M, Wu Q, Yang F, Fu B, Lai Z, Balmus G, Belotserkovskaya R, Serra V, O'Connor MJ, Bruna A, Beli P, Pellegrini L, Caldas C, Deriano L, Jacobs JJL, Galanty Y, Jackson SP. 2018. Shieldin complex promotes DNA end-joining and counters homologous recombination in BRCA1-null cells. Nature Cell Biology 20:954-965. doi:10.1038/s41556-018-0140-1

di Virgilio M, Callen E, Yamane A, Zhang W, Jankovic M, Gitlin AD, Feldhahn N, Resch W, Oliveira TY, Chait BT, Nussenzweig A, Casellas R, Robbiani DF, Nussenzweig MC. 2013. Rif1 prevents resection of DNA breaks and promotes immunoglobulin class switching. Science 339:711715. doi:10.1126/science.1230624 
Escribano-Díaz C, Orthwein A, Fradet-Turcotte A, Xing M, Young JTF, Tkáč J, Cook MA, Rosebrock AP, Munro M, Canny MD, Xu D, Durocher D. 2013. A Cell Cycle-Dependent Regulatory Circuit Composed of 53BP1RIF1 and BRCA1-CtIP Controls DNA Repair Pathway Choice. Molecular Cell 49:872-883. doi:10.1016/j.molcel.2013.01.001

Evers B, Jonkers J. 2006. Mouse models of BRCA1 and BRCA2 deficiency: Past lessons, current understanding and future prospects. Oncogene. doi:10.1038/sj.onc. 1209871

Farmer H, McCabe H, Lord CJ, Tutt AHJ, Johnson DA, Richardson TB, Santarosa M, Dillon KJ, Hickson I, Knights C, Martin NMB, Jackson SP, Smith GCM, Ashworth A. 2005. Targeting the DNA repair defect in BRCA mutant cells as a therapeutic strategy. Nature 434:917-921. doi: $10.1038 /$ nature 03445

Feng L, Fong KW, Wang J, Wang W, Chen J. 2013. RIF1 counteracts BRCA1-mediated end resection during DNA repair. Journal of Biological Chemistry 288:11135-11143. doi:10.1074/jbc.M113.457440

Findlay S, Heath J, Luo VM, Malina A, Morin T, Coulombe Y, Djerir B, Li Z, Samiei A, Simo-cheyou E, Karam M, Bagci H, Rahat D, Grapton D, Lavoie EG, Dove C, Khaled H, Kuasne H, Mann KK, Klein KO, Greenwood CM, Tabach Y, Park M, Côté J-F, Masson J-Y, Maréchal A, Orthwein A. 2018. SHLD2/FAM35A co-operates with REV7 to coordinate DNA double-strand break repair pathway choice. The EMBO Journal 37:1-20. doi:10.15252/embj.2018100158

Garzón J, Ursich S, Lopes M, Hiraga S, Donaldson AD. 2019. Human RIF1Protein Phosphatase 1 Prevents Degradation and Breakage of Nascent DNA on Replication Stalling. Cell Reports 27:2558-2566. doi:10.1016/j.celrep.2019.05.002

Ghezraoui H, Oliveira C, Becker JR, Bilham K, Moralli D, Anzilotti C, Fischer R, Deobagkar-lele M, Sanchiz-calvo M, Fueyo-marcos E, Bonham S, Kessler BM, Rottenberg S, Cornall RJ, Green CM, Chapman JR. 2018. 53BP1 cooperation with the REV7-shieldin complex underpins DNA structure-specific NHEJ. Nature 560:122-127. doi:10.1038/s41586-0180362-1

Gupta R, Somyajit K, Narita T, Maskey E, Stanlie A, Kremer M, Typas D, Lammers M, Mailand N, Nussenzweig A, Lukas J, Choudhary C. 2018. DNA Repair Network Analysis Reveals Shieldin as a Key Regulator of NHEJ and PARP Inhibitor Sensitivity. Cell 173:972-988. doi:10.1016/j.cell.2018.03.050

Hakim O, Resch W, Yamane A, Klein I, Kieffer-Kwon KR, Jankovic M, Oliveira T, Bothmer A, Voss TC, Ansarah-Sobrinho C, Mathe E, Liang G, Cobell J, Nakahashi H, Robbiani DF, Nussenzweig A, Hager GL, Nussenzweig MC, Casellas R. 2012. DNA damage defines sites of recurrent chromosomal translocations in B lymphocytes. Nature 484:69-74. doi:10.1038/nature10909

Ishida T, Kinoshita K. 2007. PrDOS: Prediction of disordered protein regions from amino acid sequence. Nucleic Acids Research 35. doi:10.1093/nar/gkm363

Jaspers JE, Kersbergen A, Boon U, Sol W, van Deemter L, Zander SA, Drost R, Wientjens E, Ji J, Aly A, Doroshow JH, Cranston A, Martin NMB, Lau A, O'Connor MJ, Ganesan S, Borst P, Jonkers J, Rottenberg S. 2013. 
Loss of 53BP1 causes PARP inhibitor resistance in BRCA1-mutated mouse mammary tumors. Cancer Discovery 3:68-81. doi:10.1158/21598290.CD-12-0049

Kumar S, Peng X, Daley J, Yang L, Shen J, Nguyen N, Bae G, Niu H, Peng Y, Hsieh HJ, Wang L, Rao C, Stephan CC, Sung P, Ira G, Peng G. 2017. Inhibition of DNA2 nuclease as a therapeutic strategy targeting replication stress in cancer cells. Oncogenesis 6. doi:10.1038/oncsis.2017.15

Liao H, Ji F, Helleday T, Ying S. 2018. Mechanisms for stalled replication fork stabilization: new targets for synthetic lethality strategies in cancer treatments. EMBO reports 19. doi:10.15252/embr.201846263

Ling AK, Munro M, Chaudhary N, Li C, Berru M, Wu B, Durocher D, Martin A. 2020. SHLD2 promotes class switch recombination by preventing inactivating deletions within the Igh locus. EMBO reports 21:e49823. doi:10.15252/embr.201949823

Methot SP, di Noia JM. 2017. Molecular Mechanisms of Somatic Hypermutation and Class Switch Recombination. Advances in Immunology 133:37-87. doi:10.1016/bs.ai.2016.11.002

Miki Yoshio, Swensen Jeff, Shattuck-Eidens Donna, Futreal P Andrew, Harshman Keith, Tavtigian Sean, Liu Qingyun, Cochran Charles, Bennett L Michelle, Ding Wei, Bell Russell, Rosenthal Judith, Hussey Charles, Tran Thanh, Mcclure Melody, Frye Cheryl, Hattier Tom, Phelps Robert, Haugen-Strano A, Katcher Harold, Yakumo Kazuko, Gholami Zahra, Shaffer Daniel, Stone Steven, Bayer Steven, Wray Christian, Bogden Robert, Dayananth Priya, Ward John, Tonin P, Narod Steven, Bristow Pam K, Norris Frank H, Helvering Leah, Morrison Paul, Rosteck Paul, Lai Mei, Barrett J Carl, Lewis Cathryn, Neuhausen Susan, Cannon-Albright Lisa, Goldgar David, Wiseman Roger, Kamb Alexander, Skolnick MH, Miki Y, Swensen J, Yakumo K, Lewis C, Neu-Hausen S, Goldgar D, Shattuck-Eidens D, Harshman K, Tavtigian S, Liu Q, Ding W, Bell R, Rosenthal J, Hussey C, Tran T, Mcclure M, Frye C, Hattier T, Phelps R, Katcher H, Gholami Z, Shaffer D, Stone S, Bayer S, Wray C, Bogden R, Dayananth P, Kamb A, Futreal P A, Cochran C, Bennett L M, HuagenStrano A, Barrett J C, Wiseman R, Ward J, Cannon-Albnght L, City L, 84132 UT, Tonin UP, Narod S, Bristow P K, Norris F H, Helvering L, Morrison P, Rosteck P, Lai M, Barrett C, Lewis C, Neuhausen S, Cannon-Albright L, Goldgar D, Wiseman R, Kamb A, Skolnick M. 1994. A Strong Candidate for the Breast and Ovarian Cancer Susceptibility Gene BRCA1. Science 266:66-71.

Monerawela C, Hiraga S, Donaldson A. 2020. Checkpoint phosphorylation sites on budding yeast Rif1 protect nascent DNA from degradation by Sgs1-Dna2. bioRxiv. doi:10.1101/2020.06.25.170571

Mukherjee C, Tripathi V, Manolika EM, Heijink AM, Ricci G, Merzouk S, de Boer HR, Demmers J, van Vugt MATMTM, Chaudhuri AR. 2019. RIF1 promotes replication fork protection and efficient restart to maintain genome stability. Nature Communications 10:1-16. doi:10.1038/s41467019-11246-1

Nakamura M, Kondo S, Sugai M, Nazarea M, Imamura S, Honjo T. 1996. High frequency class switching of an $\lg \mathrm{M}+\mathrm{B}$ lymphoma clone $\mathrm{CH} 12 \mathrm{~F} 3$ to $\lg \mathrm{A}+$ cells. International Immunology 8:193-201. 
Neelsen KJ, Lopes M. 2015. Replication fork reversal in eukaryotes: From dead end to dynamic response. Nature Reviews Molecular Cell Biology. doi:10.1038/nrm3935

Noordermeer SM, Adam S, Setiaputra D, Barazas M, Pettitt SJ, Ling AK, Olivieri M, Álvarez-quilón A, Moatti N, Zimmermann M, Annunziato S, Krastev DB, Song F, Brandsma I, Frankum J, Brough R, Sherker A, Landry S, Szilard RK, Munro MM, Mcewan A, de Rugy TG, Lin Z-Y, Hart T, Moffat J, Gingras A, Martin A, van Attikum H, Jonkers J, Lord CJ, Rottenberg S, Durocher D. 2018. The shieldin complex mediates 53BP1dependent DNA. Nature 560:117-121. doi:10.1038/s41586-018-0340-7

Panchakshari RA, Zhang X, Kumar V, Du Z, Wei P, Kao J, Dong J, Alt FW. 2018. DNA double-strand break response factors influence end-joining features of $\mathrm{lgH}$ class switch and general translocation junctions. Proceedings of the National Academy of Sciences 115:762-767. doi:10.1073/pnas.1719988115

Pasero P, Vindigni A. 2017. Nucleases Acting at Stalled Forks: How to Reboot the Replication Program with a Few Shortcuts. Annu Rev Genet 51:477-499. doi:10.1146/annurev-genet-120116

Reina-San-Martin B, Chen J, Nussenzweig A, Nussenzweig MC. 2007. Enhanced intra-switch region recombination during immunoglobulin class switch recombination in 53BP1-/- B cells. European Journal of Immunology 37:235-239. doi:10.1002/eji.200636789

Rickman K, Smogorzewska A. 2019. Advances in understanding DNA processing and protection at stalled replication forks. Journal of Cell Biology 218:1096-1107.

Rottenberg S, Jaspers JE, Kersbergen A, van der Burg E, Nygren AOH, Zander SAL, Derksen PWB, de Bruin M, Zevenhoven J, Lau A, Boulter R, Cranston A, O'connor MJ, Martin NMB, Borst P, Jonkers J. 2008. High sensitivity of BRCA1-deficient mammary tumors to the PARP inhibitor AZD2281 alone and in combination with platinum drugs.

Saha T, Sundaravinayagam D, di Virgilio M. 2021. Charting a DNA Repair Roadmap for Immunoglobulin Class Switch Recombination. Trends in Biochemical Sciences 46:184-199. doi:10.1016/j.tibs.2020.10.005

Schlacher K, Christ N, Siaud N, Egashira A, Wu H, Jasin M. 2011. Doublestrand break repair-independent role for BRCA2 in blocking stalled replication fork degradation by MRE11. Cell 145:529-542. doi:10.1016/j.cell.2011.03.041

Schlacher K, Wu H, Jasin M. 2012. A Distinct Replication Fork Protection Pathway Connects Fanconi Anemia Tumor Suppressors to RAD51BRCA1/2. Cancer Cell 22:106-116. doi:10.1016/j.ccr.2012.05.015

Scully R, Panday A, Elango R, Willis NA. 2019. DNA double-strand break repair-pathway choice in somatic mammalian cells. Nature Reviews Molecular Cell Biology 20:698-714. doi:10.1038/s41580-019-0152-0

Silverman J, Takai H, Buonomo SBC, Eisenhaber F, de Lange T. 2004. Human Rif1, ortholog of a yeast telomeric protein, is regulated by ATM and 53BP1 and functions in the S-phase checkpoint. Genes and Development 18:2108-2119. doi:10.1101/gad.1216004

Singh A, Xu Y. 2016. The Cell Killing Mechanisms of Hydroxyurea. Genes 7:1-15. doi:10.3390/genes7110099 
Smolka MB, Albuquerque CP, Chen S-H, Zhou H. 2007. Proteome-wide identification of in vivo targets of DNA damage checkpoint kinases. Proceedings of the National Academy of Sciences 104:10364-10369.

Sreesankar E, Senthilkumar R, Bharathi V, Mishra RK, Mishra K. 2012. Functional diversification of yeast telomere associated protein, Rif1, in higher eukaryotes. BMC Genomics 13. doi:10.1186/1471-2164-13-255

Sridhar A, Kedziora S, Donaldson AD. 2014. At Short Telomeres Tel1 Directs Early Replication and Phosphorylates Rif1. PLoS Genetics 10. doi:10.1371/journal.pgen.1004691

Sundaravinayagam D, Rahjouei A, Andreani M, Tupiṇa D, Balasubramanian S, Saha T, Delgado-Benito V, Coralluzzo V, Daumke O, di Virgilio M. 2019. 53BP1 Supports Immunoglobulin Class Switch Recombination Independently of Its DNA Double-Strand Break End Protection Function. Cell Reports 28:1389-1399. doi:10.1016/j.celrep.2019.06.035

Symington LS. 2016. Mechanism and regulation of DNA end resection in eukaryotes. Critical Reviews in Biochemistry and Molecular Biology 51:195-212. doi:10.3109/10409238.2016.1172552

Tarsounas M, Sung P. 2020. The antitumorigenic roles of BRCA1-BARD1 in DNA repair and replication. Nature Reviews Molecular Cell Biology. doi:10.1038/s41580-020-0218-z

Wang J, Zhang H, al Shibar M, Willard B, Ray A, Runge KW. 2018. Rif1 phosphorylation site analysis in telomere length regulation and the response to damaged telomeres. DNA Repair 65. doi:10.1016/j.dnarep.2018.03.001

Wright PE, Dyson HJ. 2015. Intrinsically disordered proteins in cellular signalling and regulation. Nature Reviews Molecular Cell Biology. doi:10.1038/nrm3920

Xu D, Muniandy P, Leo E, Yin J, Thangavel S, Shen X, li M, Agama K, Guo R, Fox D, Meetei AR, Wilson L, Nguyen H, Weng NP, Brill SJ, Li L, Vindigni A, Pommier Y, Seidman M, Wang W. 2010. Rif1 provides a new DNAbinding interface for the Bloom syndrome complex to maintain normal replication. EMBO Journal 29:3140-3155. doi:10.1038/emboj.2010.186

Xu G, Chapman JR, Brandsma I, Yuan J, Mistrik M, Bouwman P, Bartkova J, Gogola E, Warmerdam D, Barazas M, Jaspers JE, Watanabe K, Pieterse M, Kersbergen A, Sol W, Celie PHN, Schouten PC, van den Broek B, Salman A, Nieuwland M, de Rink I, de Ronde J, Jalink K, Boulton SJ, Chen J, van Gent DC, Bartek J, Jonkers J, Borst P, Rottenberg S. 2015. REV7 counteracts DNA double-strand break resection and affects PARP inhibition. Nature 521:541-544. doi:10.1038/nature14328

Xu X, Qiao W, Linke SP, Cao L, Li W-M, Furth PA, Harris CC, Deng C-X. 2001. Genetic interactions between tumor suppressors Brca1 and p53 in apoptosis, cell cycle and tumorigenesis. Nature Genetics 28:266-271.

Xu X, Wagner K-U, Larson D, Weaver Z, Li C, Ried T, Hennighausen L, Wynshaw-Boris A, Deng C-X. 1999. Conditional mutation of Brca1 in mammary epithelial cells results in blunted ductal morphogenesis and tumour formation. Nature Genetics 22:37-42.

Yamane A, Robbiani DF, Resch W, Bothmer A, Nakahashi H, Oliveira T, Rommel PC, Brown EJ, Nussenzweig A, Nussenzweig MC, Casellas R. 2013. RPA Accumulation during Class Switch Recombination Represents 
5'-3' DNA-End Resection during the S-G2/M Phase of the Cell Cycle. Cell Reports 3:138-147. doi:10.1016/j.celrep.2012.12.006

Yewdell WT, Chaudhuri J. 2017. A transcriptional serenAID: The role of noncoding RNAs in class switch recombination. International Immunology 29:183-196. doi:10.1093/intimm/dxx027

Zarin T, Strome B, Nguyen Ba AN, Alberti S, Forman-Kay JD, Moses AM. 2019. Proteome-wide signatures of function in highly diverged intrinsically disordered regions. eLife 8. doi:10.7554/eLife.46883

Zarin T, Tsai CN, Ba ANN, Moses AM. 2017. Selection maintains signaling function of a highly diverged intrinsically disordered region. Proceedings of the National Academy of Sciences of the United States of America 114:E1450-E1459. doi:10.1073/pnas.1614787114

Zimmermann M, Lottersberger F, Buonomo SB, Sfeir A, de Lange T. 2013. 53BP1 Regulates DSB Repair Using Rif1 to Control 5' End Resection. Science 339:700-704. 


\section{List of Figures}

Figure 1. A conserved cluster of SQ motifs within RIF1 intrinsically disordered region is phosphorylated in activated B lymphocytes.

Figure 2. Phosphorylation of RIF1 at the conserved IDR-CII SQ motifs is dispensable for its roles in DSB end protection.

Figure 3. Phosphorylation of the conserved IDR-CII SQ cluster enables RIF1-dependent protection of nascent DNA at stalled replication forks.

Figure S1. BRCA1-mutated $\mathrm{CH} 12$ cell lines recapitulate the genomic instability of BRCA1 deficiency.

Figure S2. Generation of RIF1-mutant $\mathrm{CH} 12$ cell lines on a BRCA1deficient background.

Figure S3. Generation of RIF1-mutant $\mathrm{CH} 12$ cell lines on a WT background.

Table S1. List of RIF1 protein homologs across representative species from the Animalia and Fungi kingdoms.

Table S2. Alignment of peptides containing SQ/TQ motifs conserved between mouse and human RIF1 proteins across representative species from the Animalia and Fungi kingdoms.

Table S3. List of oligonucleotides used in this study. 


\section{List of source data files}

\section{Figure 1-source data 1.tiff}

Original file for the western blot analysis in Figure 1 panel C (anti-FLAG, antiRIF1, and anti-Tubulin).

\section{Figure 1-source data 1 with labels.pdf}

Pdf file containing Figure 1 panel $\mathrm{C}$ and original scans of the relevant western blot analysis (anti-FLAG, anti-RIF1, and anti-Tubulin) with highlighted bands and sample labels.

\section{Figure 1-source data 2.xIsx}

Excel file containing output results of MaxQuant analysis for the potential RIF1 interactors for graph in Figure 1 panel $D$. Protein $H /(H+L)$ ratios were derived using peptides' H/L intensity values in MaxQuant output.

\section{Figure 2-source data 1.tif}

Original file for the western blot analysis in Figure 2 panel $F$ (anti-RIF1).

\section{Figure 2-source data 2.tiff}

Original file for the western blot analysis in Figure 2 panel $F$ (anti- $\beta$ Actin).

\section{Figure 2-source data 1 and 2 with labels.pdf}

Pdf file containing Figure 2 panel $F$ and original scans of the relevant western blot analysis (anti-RIF1 and anti- $\beta$ Actin) with highlighted bands and sample labels.

\section{Figure 3-source data 1-right side.tif}

Original file for the western blot analysis in Figure 3 panel A (anti-RIF1 and anti- $\beta$ Actin).

\section{Figure 3-source data 1 with labels.pdf}


Pdf file containing Figure 3 panel A and original scans of the relevant western blot analysis (anti-RIF1 and anti- $\beta$ Actin) with highlighted bands and sample labels.

\section{Figure 2-figure supplement 2-source data 1.jpg}

Original file for the western blot analysis in Figure S2 panel C (anti-RIF1 and

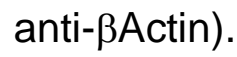

\section{Figure 2-figure supplement 2-source data 1 with labels.pdf}

Pdf file containing Figure S2 panel $\mathrm{C}$ and original scans of the relevant western blot analysis (anti-RIF1 and anti- $\beta$ Actin) with highlighted bands and sample labels.

\section{Figure 3-figure supplement 3-source data 1-left side.tif}

Original file for the western blot analysis in Figure S3 panel B (anti-RIF1 and anti- $\beta$ Actin).

\section{Figure 3-figure supplement 3-source data 1 with labels.pdf}

Pdf file containing Figure S3 panel B and original scans of the relevant western blot analysis (anti-RIF1 and anti- $\beta$ Actin) with highlighted bands and sample labels. 